\title{
Modeling CST Ion-Exchange for Cesium Removal from SCIX Batches 1 - 4
}

\author{
F. G. Smith, III
}

APRIL 25, 2011

Savannah River National Laboratory Savannah River Nuclear Solutions Savannah River Site Aiken, SC 29808

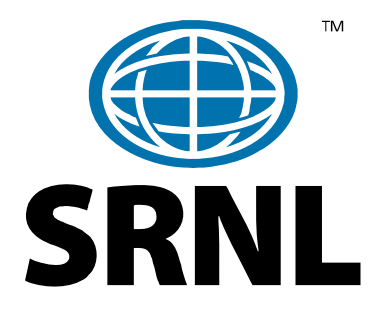




\section{DISCLAIMER}

This work was prepared under an agreement with and funded by the U.S. Government. Neither the U. S. Government or its employees, nor any of its contractors, subcontractors or their employees, makes any express or implied:

1. warranty or assumes any legal liability for the accuracy, completeness, or for the use or results of such use of any information, product, or process disclosed; or

2. representation that such use or results of such use would not infringe privately owned rights; or

3. endorsement or recommendation of any specifically identified commercial product, process, or service.

Any views and opinions of authors expressed in this work do not necessarily state or reflect those of the United States Government, or its contractors, or subcontractors.

Printed in the United States of America

Prepared For

U.S. Department of Energy 


\title{
KEYWORDS:
}

Ion Exchange

Column Modeling

Crystalline Silicotitanate

Cesium Removal

VERSE-LC Code

RETENTION

Permanent

\section{Modeling CST Ion-Exchange for Cesium Removal from SCIX Batches 1 - 4}

\author{
F. G. Smith, III
}

APRIL 25, 2011

Savannah River National Laboratory

Savannah River Nuclear Solutions

Savannah River Site

Aiken, SC 29808

Prepared for the U.S. Department of Energy Under

Contract Number DE-AC09-08SR22470 


\section{REVIEWS AND APPROVALS}

DOCUMENT: SRNL-STI-2011-00181, Rev. 0

TITLE: Modeling CST Ion-Exchange for Cesium Removal from SCIX Batches 1 - 4

Date:

F. G. Smith, Author

SRNL-CSS-PMCC

Date:

T. Hang, Technical Reviewer

SRNL-CSS-PMCC

Date:

S. J. Hensel, Level 4 Manager

SRNL-CSS-PMCC

Date:

F. M. Pennebaker, Level 4 Manager

SRNL-ERPS-ACPT

Date:

T. H. Huff, Design Authority Manager

SRR-SCIX Engineering 


\section{TABLE OF CONTENTS}

\begin{tabular}{|c|c|}
\hline .0 & EXECUTIVE SUMMARY \\
\hline 1.1 & MODELING APPROACH \\
\hline 1.2 & TY ASSURANCE .... \\
\hline 1.3 & RESULTS SUMMARY ....... \\
\hline 2.0 & INTRODUCTION AND BACKGROUND \\
\hline 2.1 & 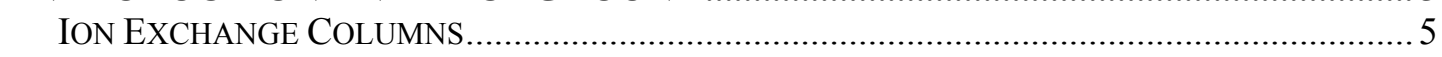 \\
\hline 2.2 & 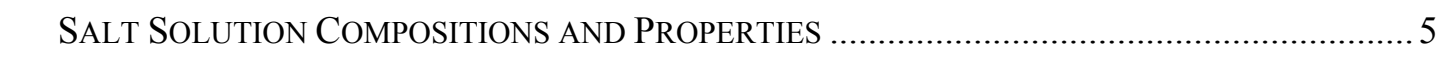 \\
\hline 2.3 & 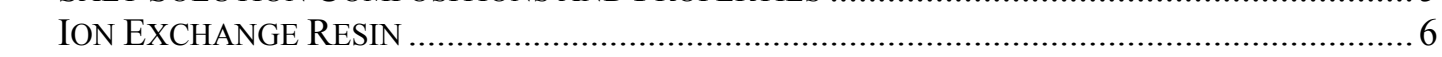 \\
\hline 2.4 & 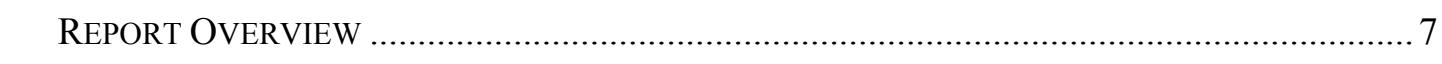 \\
\hline 3.0 & VERSE-LC COLUMN MODEL ...... \\
\hline 3.1 & SINGLE-COMPONENT MODEL ............ \\
\hline 4.0 & CESIUM ISOTHERMS .......................... \\
\hline 4.1 & ISOTHERM MODEL FOR VERSE-LC APPLICATION ........................... \\
\hline 5.0 & COLUMN PROPERTIES.......................... \\
\hline 5.1 & BASIC CONSTRAINT FUNCTIONS................... \\
\hline 5.2 & CST MEDIA PROPERTIES ............... \\
\hline 6.0 & 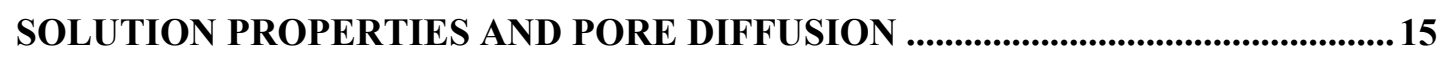 \\
\hline 6.1 & 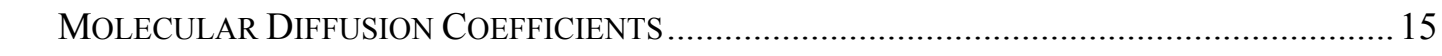 \\
\hline 6.2 & 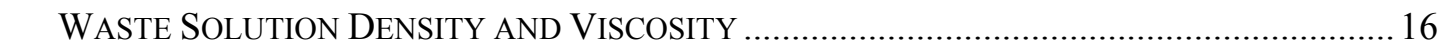 \\
\hline 6.3 & 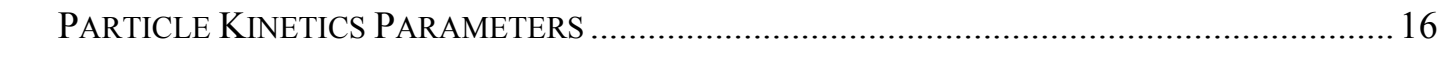 \\
\hline 7.0 & 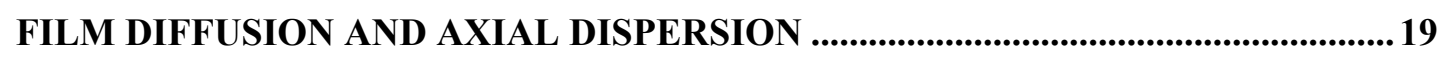 \\
\hline 7.1 & FILM DIFFUSION \\
\hline 7.2 & AXIAL DISPERSION .... \\
\hline 8.0 & 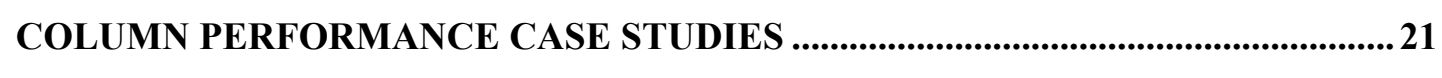 \\
\hline 9.0 & MODELING RESULTS................. \\
\hline 9.1 & CST ISOTHERM PARAMETERS .... \\
\hline 9.2 & 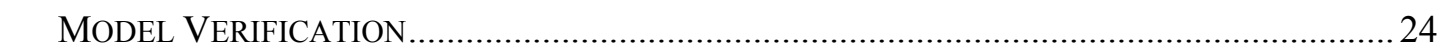 \\
\hline 9.3 & CST ION-EXCHANGE COLUMN MODELING RESULTS .... \\
\hline 10.0 & CONCLUSIONS \\
\hline & )$^{2}$ \\
\hline
\end{tabular}




\section{LIST OF TABLES}

Table 1-1. Volume in thousands of gallons processed through SCIX ion-exchange columns during first cycle.

Table 1-2. Volume processed through SCIX ion-exchange columns during first cycle relative to nominal operating conditions.

Table 1-3. Volume in thousands of gallons processed through SCIX ion-exchange columns during three cycles at nominal processing conditions. ......................................................... 4

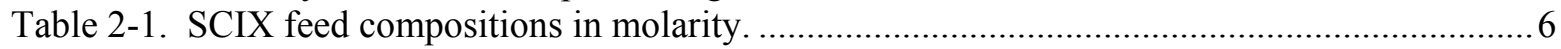

Table 6-1. Limiting ionic conductivity fitting coefficients and calculated conductivities in water at $25^{\circ} \mathrm{C}$

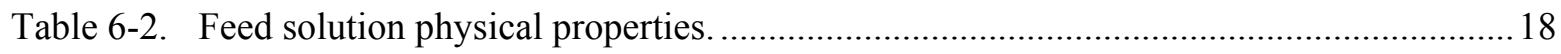

Table 8-1. VERSE-LC case study matrix of feed flows and column temperatures.......................2 21

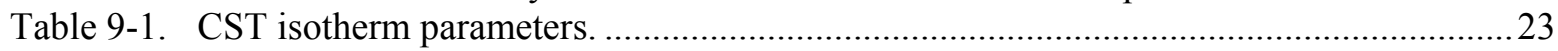

Table 9-2. Tank 44 sample composition in molarity..............................................................25

Table 9-3. Volume in thousands of gallons processed through SCIX ion-exchange columns during

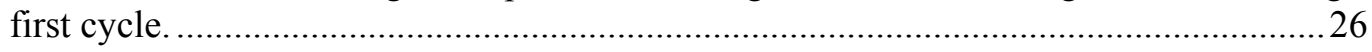

Table 9-4. Volume in thousands of gallons processed through SCIX ion-exchange columns during three cycles at nominal processing conditions. 


\section{LIST OF FIGURES}

Figure 9-1. Cesium isotherm for SCIX Feed Batch 1 at $35^{\circ} \mathrm{C}$. 24

Figure 9-2. Cesium breakthrough data for CST IE-911 with actual SRS Tank 44 waste (Walker et al., 1999) and ZAM/VERSE-LC model prediction.................................................25

Figure 9-3. Lag column breakthrough curves for SCIX Batches 1-4 at nominal operating conditions of $35^{\circ} \mathrm{C}$ and $10 \mathrm{gpm}$ flow rate.

Figure 9-4. Cesium profile in columns at end of cycle for Batch 1 SCIX feed as a function of flow rate at $35^{\circ} \mathrm{C}$.

Figure 9-5. Cesium profile in columns at end of cycle for Batch 1 SCIX feed as a function of temperature at $10 \mathrm{gpm}$ flow.

Figure 9-6. Cesium profile in columns at end of cycle for Batch 2 SCIX feed as a function of flow rate at $35^{\circ} \mathrm{C}$.

Figure 9-7. Cesium profile in columns at end of cycle for Batch 2 SCIX feed as a function of temperature at 10 gpm flow. ...................................................................................29

Figure 9-8. Cesium profile in columns at end of cycle for Batch 3 SCIX feed as a function of flow rate at $35^{\circ} \mathrm{C}$.

Figure 9-9. Cesium profile in columns at end of cycle for Batch 3 SCIX feed as a function of temperature at 10 gpm flow.

Figure 9-10. Cesium profile in columns at end of cycle for Batch 4 SCIX feed as a function of flow rate at $35^{\circ} \mathrm{C}$.

Figure 9-11. Cesium profile in columns at end of cycle for Batch 4 SCIX feed as a function of temperature at 10 gpm flow.

Figure 9-12. Cesium profile in columns at end of cycle for Batch 1 SCIX feed without caustic addition as a function of flow rate at $35^{\circ} \mathrm{C}$.

Figure 9-13. Cesium profile in columns at end of cycle for Batch 1 SCIX feed without caustic addition as a function of temperature at $10 \mathrm{gpm}$ flow

Figure 9-14. Cesium profile in columns at end of cycle for Batch 2 SCIX feed without caustic addition as a function of flow rate at $35^{\circ} \mathrm{C}$.

Figure 9-15. Cesium profile in columns at end of cycle for Batch 2 SCIX feed without caustic addition as a function of temperature at $10 \mathrm{gpm}$ flow 
SRNL-STI-2011-00181 Rev. 0

(This Page Intentionally Left Blank) 


\subsection{Executive Summary}

The objective of this work is, through modeling, to predict the performance of Crystalline Silicotitinate (CST) for the removal of cesium from Small Column Ion Exchange (SCIX) Batches $1-4$ (as proposed in Revision 16 of the Liquid Waste System Plan). The scope of this task is specified in Technical Task Request (TTR) "SCIX Feed Modeling", HLE-TTR2011-003, which specified using the Zheng, Anthony, Miller (ZAM) code to predict CST isotherms for six given SCIX feed compositions and the VErsatile Reaction and SEparation simulator for Liquid Chromatography (VERSE-LC) code to predict ion-exchange column behavior. The six SCIX feed compositions provided in the TTR represent SCIX Batches $1-$ 4 and Batches 1 and 2 without caustic addition. The study also investigated the sensitivity in column performance to:

1. Flow rates of 5, 10, and $20 \mathrm{gpm}$ with $10 \mathrm{gpm}$ as the nominal flow.

2. Temperatures of 25,35 , and $45^{\circ} \mathrm{C}$ with $35^{\circ} \mathrm{C}$ as the nominal temperature.

The isotherms and column predictions presented in this report reflect the expected performance of engineered CST IE-911. This form of CST was used in experiments conducted at the Savannah River National Laboratory (SRNL) that formed the basis for estimating model parameters (Hamm et al., 2002). As has been done previously, the engineered resin capacity is estimated to be $68 \%$ of the capacity of particulate CST without binder.

\subsection{Modeling Approach}

- An Excel spreadsheet was created to calculate charge balanced SCIX feed compositions by adjusting the hydroxyl ion concentrations and to calculate cesium diffusion coefficients.

- The OLI Analyzer Studio ${ }^{\mathrm{TM}}$ software was used to estimate feed solution density and viscosity.

- The ZAM code, developed at Texas A\&M University, which contains detailed thermodynamic equilibrium models of CST adsorption behavior, was used to calculate effective cesium adsorption isotherms for each SCIX feed composition. Output from the ZAM code was fit to a Langmuir isotherm using an Excel spreadsheet.

- The VERSE-LC code, developed at Purdue University, which models ion-exchange columns including ion transport into porous resin particles, was used to simulated SCIX column performance.

Based on this methodology, "best estimate" column simulations were run for the six SCIX feed streams assuming a two-column (lead-lag) configuration. A limit on the bucket average concentration (i.e., the integrated effluent cesium concentration) was imposed at the exit of the lag column. Because VERSE-LC does not have the built-in capability of calculating a bucket average effluent concentration, this calculation was performed in an Excel spreadsheet using output from VERSE-LC. 


\subsection{Quality Assurance}

The ZAM code (Version 4) has been used in previous SRNL studies modeling cesium adsorption on CST with good success (Hamm et al., 2002; Aleman, 2003; Smith, 2007). The Liquid Chromatography code VERSE-LC (Whitley and Wang, 1998) was used to perform the ion-exchange column calculations. Prior to applying VERSE-LC in ion exchange modeling tasks, a model verification process was completed and the results of that effort were reported by Hamm et al. (2000). The verification process provided quality assurance that the installed Windows version of VERSE-LC (Version 7.80) was capable of accurately solving the model equations and also helped to understand how to use the VERSE-LC code (e.g., mesh refinement requirements and input/output options). For all column results presented in this report, numerical errors associated with the results from VERSE-LC should be very small when compared to the uncertainties associated with various model input parameters such as bed density, particle radius, and pore diffusion.

\subsection{Results Summary}

The bucket average cesium concentration limit in the lag column effluent was specified to be $6.0 \mathrm{nCi} / \mathrm{g}$. Table 1-1 lists the predicted volume of each batch that can be processed during an ion-exchange cycle (i.e. operation of the ion-exchange system until the effluent limit is reached and fresh resin must be added) starting with fresh resin in each column at the flow rates and temperatures tested. In all cases, the ZAM isotherm predicts a relatively high capacity of the CST resin for cesium adsorption which means that a significant volume of salt solution can be processed in each ion-exchange cycle. Table 1-2 shows the batch volume that can be processed in each ion-exchange cycle relative to the volume processed under nominal operating conditions. Table 1-3 shows the volume of solution that can be processed through three ion-exchange cycles where, at the end of each cycle, the lag column is placed in the lead position and a fresh column placed in the lag position.

General trends in the modeling results are:

- Cesium loading on the CST was predicted to be significantly higher than found in the previous study (Smith, 2007). This was primarily caused by the increased hydroxide concentration in the feed composition.

- All of the SCIX batches behaved similarly and caustic adjustment of the feeds resulted in only small decreases in the volume processed per cycle.

- Using a lower flow rate relative to the nominal $10 \mathrm{gpm}$ sharpens the breakthrough front and allows more volume to be processed in each ion-exchange cycle. Decreasing the column flow from $10 \mathrm{gpm}$ to $5 \mathrm{gpm}$ on average increases the volume of solution processed in each ion-exchange cycle by $26 \%$ while at the same time doubling the time required to run the material through the column.

- Conversely, using a higher flow rate spreads out the breakthrough front and decreases the amount of solution that can be processed in each ion-exchange cycle. Doubling the flow from $10 \mathrm{gpm}$ to $20 \mathrm{gpm}$ on average decreases the volume of 
solution processed in each ion-exchange cycle by $30 \%$ while also decreasing the time required to run the material through the column by a factor of two.

- Operating the column at higher temperature decreases the adsorption capacity of the resin and decreases the amount of solution that can be treated in each cycle. Operating at $45^{\circ} \mathrm{C}$ instead of $35^{\circ} \mathrm{C}$ on average decreases the CST capacity by $16 \%$.

- Conversely, operating the column at lower temperature increases the adsorption capacity of the resin and increases the amount of solution that can be treated in each cycle. Operating at $25^{\circ} \mathrm{C}$ instead of $35^{\circ} \mathrm{C}$ on average increases the CST capacity by $18 \%$.

- At the nominal operating conditions of $10 \mathrm{gpm}$ and $35^{\circ} \mathrm{C}$, starting with two fresh columns at the start of processing, it will take between two and three ion-exchange cycles per batch to process SCIX Batches $1-4$. The model predicts that SCIX Batch 3 would require slightly more than three ion-exchange cycles under nominal operating conditions.

- Under nominal operating conditions, an additional 41,000 gallons of feed solution can be processed using a bucket average effluent cesium concentration of $6.0 \mathrm{nCi} / \mathrm{g}$ as the end point instead of an absolute effluent concentration of $6.0 \mathrm{nCi} / \mathrm{g}$.

- At the end of each cycle, under nominal operating conditions, the lead column will be loaded to greater than $98 \%$ of full capacity while the lag column will be from $20 \%$ to $40 \%$ loaded.

- For the SCIX feed compositions given in Table 2-1, strontium does not load onto CST to any significant extent. On average, increasing the rubidium concentration in the feed by a factor of 10 decreased cesium loading by $3 \%$.

Plots showing results for each case run are presented in Section 9.

Table 1-1. Volume in thousands of gallons processed through SCIX ion-exchange columns during first cycle.

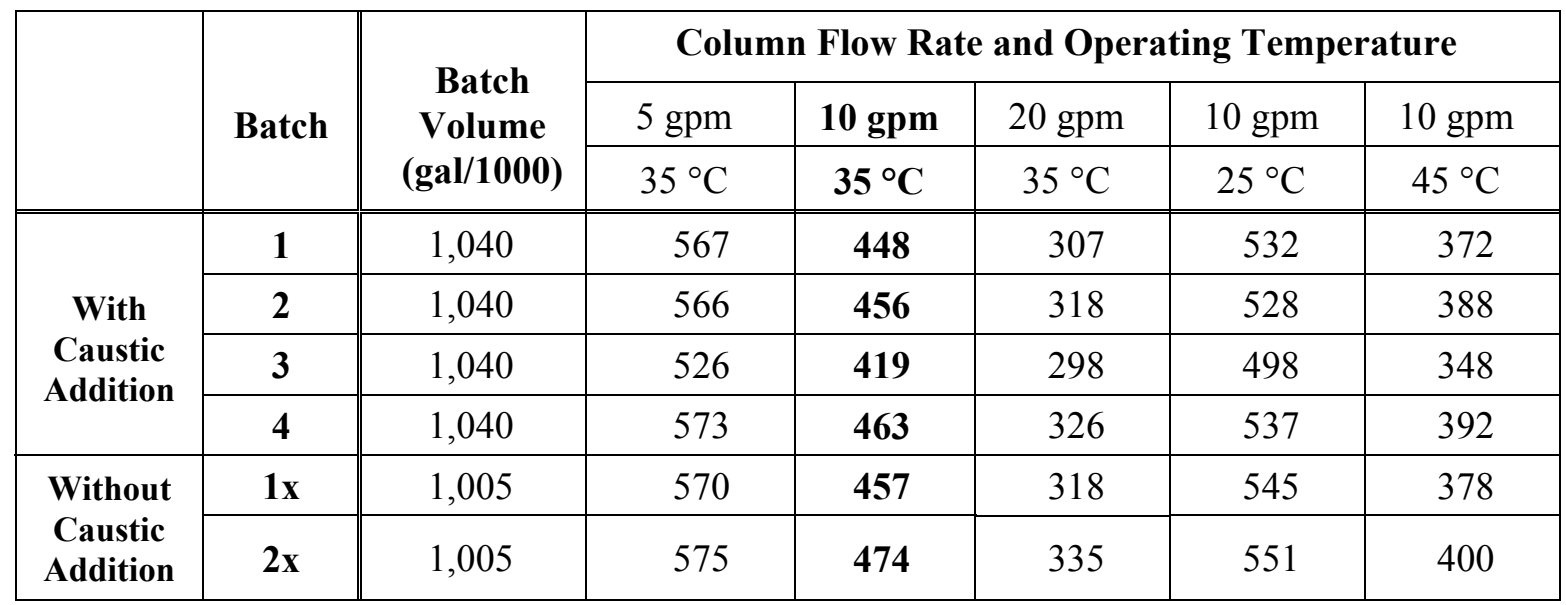


Table 1-2. Volume processed through SCIX ion-exchange columns during first cycle relative to nominal operating conditions.

\begin{tabular}{|c|c|c|c|c|c|c|c|}
\hline & \multirow{3}{*}{ Batch } & \multirow{3}{*}{$\begin{array}{c}\text { Batch } \\
\text { Volume } \\
\text { (gal/1000) }\end{array}$} & \multicolumn{5}{|c|}{ Column Flow Rate and Operating Temperature } \\
\hline & & & $5 \mathrm{gpm}$ & $10 \mathrm{gpm}$ & $20 \mathrm{gpm}$ & $10 \mathrm{gpm}$ & $10 \mathrm{gpm}$ \\
\hline & & & $35^{\circ} \mathrm{C}$ & $35^{\circ} \mathrm{C}$ & $35^{\circ} \mathrm{C}$ & $25^{\circ} \mathrm{C}$ & $45^{\circ} \mathrm{C}$ \\
\hline \multirow{4}{*}{$\begin{array}{c}\text { With } \\
\text { Caustic } \\
\text { Addition }\end{array}$} & 1 & 1,040 & 1.27 & 1 & 0.68 & 1.19 & 0.83 \\
\hline & 2 & 1,040 & 1.24 & 1 & 0.70 & 1.16 & 0.85 \\
\hline & 3 & 1,040 & 1.26 & 1 & 0.71 & 1.19 & 0.83 \\
\hline & 4 & 1,040 & 1.24 & 1 & 0.70 & 1.16 & 0.85 \\
\hline \multirow{2}{*}{$\begin{array}{l}\text { Without } \\
\text { Caustic } \\
\text { Addition }\end{array}$} & $\mathbf{1 x}$ & 1,005 & 1.25 & 1 & 0.70 & 1.19 & 0.83 \\
\hline & $2 x$ & 1,005 & 1.27 & 1 & 0.68 & 1.19 & 0.83 \\
\hline \multicolumn{2}{|c|}{ Average Change } & & 1.26 & & 0.70 & 1.18 & 0.84 \\
\hline
\end{tabular}

Table 1-3. Volume in thousands of gallons processed through SCIX ion-exchange columns during three cycles at nominal processing conditions.

\begin{tabular}{|c|c||c|c|c||c|}
\hline & \multicolumn{1}{|c||}{$\begin{array}{c}\text { SCIX } \\
\text { Batch }\end{array}$} & \multicolumn{4}{c|}{ Volume Processed (gal/1000) } \\
\cline { 2 - 6 } & Cycle 1 & Cycle 2 & Cycle 3 & Total \\
\hline \hline \multirow{4}{*}{$\begin{array}{c}\text { With } \\
\text { Caustic } \\
\text { Addition }\end{array}$} & $\mathbf{1}$ & 448 & 315 & 340 & 1,103 \\
\cline { 2 - 6 } & $\mathbf{2}$ & 456 & 314 & 334 & 1,104 \\
\cline { 2 - 6 } & $\mathbf{3}$ & 419 & 287 & 315 & 1,021 \\
\hline $\begin{array}{c}\text { Without } \\
\text { Caustic } \\
\text { Addition }\end{array}$ & $\mathbf{1 x}$ & 463 & 316 & 339 & 1,118 \\
\cline { 2 - 6 } & $\mathbf{2 x}$ & 457 & 316 & 338 & 1,111 \\
\hline
\end{tabular}




\subsection{Introduction and Background}

The SCIX process will be used to remove cesium from supernate and dissolved saltcake in Savannah River Site (SRS) waste tanks. Using ion-exchange columns suspended inside a waste tank, the columns will use a selective ion-exchange media to remove cesium from the waste. The media removes all isotopes of cesium, about $25 \%$ of which, on a mole basis, is the radioactive Cs-137 isotope. The ion-exchange resin that will be used for this process is non-elutable CST in its engineered form. After sorption of cesium, the non-elutable CST will be sluiced from the lead column in the SCIX system, the partially loaded lag column will be placed into the lead position, and a fresh batch of CST loaded into the lag column for continued operation. The purpose of this modeling effort is to provide input to the expected operation of this system.

\subsection{Ion Exchange Columns}

The ion-exchange column design was developed by Oak Ridge National Laboratory (ORNL) and SRNL. The design overcame earlier issues related to column overheating and long contact time by using an annular configuration with an outer diameter of 28 inches and a 6-inch diameter inner cooling tube. The outer tube has a wall thickness of 3/8-inch and the inner tube is 6-inch schedule 40 pipe. The cross-sectional area of the annular ionexchange bed is calculated to be $0.354 \mathrm{~m}^{2}$.

The proposed design consists of two columns used in series (i.e., a lead column followed by a lag column). When the average integrated concentration of cesium in the effluent from the second (lag) column reaches the limit of $6.0 \mathrm{nCi} / \mathrm{g}$, the ion-exchange cycle is stopped. At this point, the spent ion-exchange resin is removed from the lead column and replaced with fresh resin. The partially loaded lag column is placed in the lead position and the freshly loaded column placed in the lag position. Modeling results show that at the end of the first cycle, when operating with initially fresh columns under nominal conditions, the lead column is nearly completely loaded and the lag column is from $20 \%$ to $40 \%$ loaded.

\subsection{Salt Solution Compositions and Properties}

Dissolved salt solution compositions were taken from the table provided in HLE-TTR-2011003 (Behrouzi, 2011) supplemented by rubidium and strontium concentrations provided separately (email from M. A. Rios-Armstrong). For reference, the compositions are listed in Table 2-1. The small strontium and rubidium concentrations are included since both strontium and rubidium are competitors for cesium on CST. Strontium concentrations in the feed to the ion-exchange columns would be reduced from the values given in Table 2-1 following treatment of the supernate with monosodium titinate (MST). Total cesium concentration in the feed solutions was estimated from the measured $\mathrm{Cs}-137 \mathrm{Ci} / \mathrm{gal}$ in each batch using a specific activity of $11,927 \mathrm{Ci} / \mathrm{g}-\mathrm{mol}$ and assuming that $\mathrm{Cs}-137$ represents $25 \%$ of the total moles of cesium. 
The density and viscosity of each solution were calculated from the composition and temperature using the OLI Analyzer Studio ${ }^{\mathrm{TM}}$ software (Version 3.1) from OLI Systems, Inc. As shown in Section 6, the cesium diffusivity in the bulk feed solution (free diffusivity) was calculated using the Nernst-Haskell equation. Based on fitting SRNL experimental data (Aleman, 2003), cesium diffusivity in CST pores is estimated to be $20 \%$ of the diffusivity in bulk liquid.

Table 2-1. SCIX feed compositions in molarity.

\begin{tabular}{|c||c|c|c|c|c|c|}
\hline & \multicolumn{3}{|c|}{ With Caustic Addition } & \multicolumn{2}{c|}{$\begin{array}{c}\text { Without Caustic } \\
\text { Addition }\end{array}$} \\
\hline \multirow{2}{*}{ Species } & Batch 1 & Batch 2 & Batch 3 & Batch 4 & Batch 1x & Batch 2x \\
\hline \hline $\mathrm{Na}^{+1}$ & 6.83 & 6.71 & 6.20 & 6.24 & 6.40 & 6.29 \\
\hline $\mathrm{NO}_{2}{ }^{-1}$ & 0.77 & 0.72 & 0.55 & 0.75 & 0.80 & 0.74 \\
\hline $\mathrm{NO}_{3}{ }^{-1}$ & 1.89 & 1.81 & 2.45 & 1.83 & 1.95 & 1.87 \\
\hline $\mathrm{OH}^{-1 \mathrm{a}}$ & 3.48 & 3.65 & 2.85 & 3.46 & 2.94 & 3.11 \\
\hline $\mathrm{OH}^{-1 b}$ & 3.35 & 3.60 & 2.67 & 3.20 & 2.80 & 3.08 \\
\hline $\mathrm{Al}\left(\mathrm{OH}_{4}\right)^{-1}$ & 0.28 & 0.14 & 0.15 & 0.21 & 0.29 & 0.14 \\
\hline $\mathrm{CO}_{3}^{-2}$ & 0.230 & 0.194 & 0.129 & 0.0804 & 0.238 & 0.201 \\
\hline $\mathrm{SO}_{4}^{-2}$ & 0.0205 & 0.0133 & 0.0405 & 0.0285 & 0.0212 & 0.0138 \\
\hline $\mathrm{PO}_{4}^{-3}$ & 0.0108 & 0.00819 & 0.0134 & 0.0118 & 0.0112 & 0.00922 \\
\hline $\mathrm{Cl}^{-1}$ & 0.00714 & 0.00796 & 0.0105 & 0.00875 & 0.00739 & 0.00823 \\
\hline $\mathrm{F}^{-1}$ & 0.0109 & 0.00742 & 0.0159 & 0.0135 & 0.0113 & 0.00768 \\
\hline $\mathrm{K}^{+1}$ & 0.0105 & 0.0168 & 0.0277 & 0.0245 & 0.0108 & 0.0174 \\
\hline $\mathrm{Cs}^{+1}$ & $1.82 \times 10^{-4}$ & $2.02 \times 10^{-4}$ & $9.57 \times 10^{-5}$ & $1.73 \times 10^{-4}$ & $1.89 \times 10^{-4}$ & $2.09 \times 10^{-4}$ \\
\hline $\mathrm{Sr}^{+2}$ & $9.23 \times 10^{-5}$ & $1.38 \times 10^{-4}$ & $9.90 \times 10^{-5}$ & $9.98 \times 10^{-5}$ & $9.55 \times 10^{-5}$ & $1.43 \times 10^{-4}$ \\
\hline $\mathrm{Rb}^{+1}$ & $5.46 \times 10^{-6}$ & $2.14 \times 10^{-5}$ & $3.87 \times 10^{-5}$ & $2.51 \times 10^{-5}$ & $5.65 \times 10^{-6}$ & $2.21 \times 10^{-5}$ \\
\hline
\end{tabular}

${ }^{\mathrm{a}}$ Hydroxyl ion concentration provided in TTR

${ }^{b}$ Hydroxyl ion concentration adjusted to charge balance solutions

\subsection{Ion Exchange Resin}

CST cation-exchange materials have been developed for the selective removal of cesium (containing some isotopic fraction of Cs-137) from highly alkaline solutions. CST will be used in the granular, engineered form. The isotherm used in this report applies for UOP IONSIV $^{\circledR}$ IE-911. Researchers at Texas A\&M University and Sandia National Laboratory developed the sorbent, and UOP personnel developed the binder technology for producing a granular form suitable for use in an ion exchange column. Based on the analysis reported by Hamm et al. (2002, Appendix C), the cesium adsorption capacity of engineered CST (IE911 ) is estimated to be $68 \%$ of the capacity of CST in particulate form (IE-910). 


\subsection{Report Overview}

The modeling methodology and its application to the proposed SCIX process are discussed in the following sections. The VERSE-LC code (Berninger et al., 1991) was used for the column modeling presented in this report based on its availability and its use in previous ion-exchange analysis efforts at SRNL (Hamm et al., 2002; Aleman, 2003; Smith, 2007). Section 3 briefly discusses the transport model used to describe ion-exchange column behavior. In the column model, local equilibrium between the pore fluid and neighboring surface sites is assumed where an equilibrium adsorption isotherm must be specified. The isotherm model used for this purpose is discussed in Section 4. Key column properties are addressed in Section 5 where the constraint imposed by bed porosity, particle porosity, and bed density is highlighted. Solution properties and diffusion in the porous ion-exchange particles are addressed in Section 6. In Section 7 the constitutive models for film diffusion and axial dispersion are presented. Section 8 lists the SCIX case studies run. Section 9 presents modeling results for the CST system. Conclusions are presented in Section 10. 


\subsection{VERSE-LC Column Model}

The modeling of ion exchange columns is typically separated into two parts:

1. An adsorption isotherm model that specifies the equilibrium relationship between the concentration of adsorbing ions in solution and the solid phase, and

2. A column model based on one-dimensional (axial) solute transport.

In order of their importance with respect to predicting column performance, the five basic aspects of the ion exchange column that need to be addressed are:

- Adsorption Isotherm (high impact) - Resin affinities for the various competing ions that adsorb have a direct impact on overall column performance. The isotherms shift the entire breakthrough curve with respect to the number of column volumes required to reach a specified concentration level and, for non-linear isotherms, alter the breakthrough curve shape as well as its sensitivity to inlet feed conditions.

- Bed Definition (high impact) - Column size, geometry, and resin mass have a direct impact on overall column performance, shifting the entire breakthrough curve with respect to the number of column volumes required to reach a specified concentration level, with particle geometry having slightly less impact.

- Pore Diffusion (moderate impact) - Intra-particle mass transport by pore diffusion to available surface sites has a moderate impact on overall column performance. Pore diffusion alters the shape of exit breakthrough curves about the $50 \%$ breakthrough concentration level with a slight shifting of the breakthrough curve. Increased pore diffusion enhances the rate of mass transfer between the liquid and solid which tends to sharpen the breakthrough curve.

- Film Diffusion (low impact) - Liquid mass transport by film diffusion across the particle-to-bed boundary has a low impact on overall column performance. Film diffusion alters the shape of exit breakthrough curves about the 50\% breakthrough concentration level with a slight shifting of the breakthrough curve.

- Axial Dispersion (low impact) - Mass transport along the column length by axial dispersion has a relatively low impact on overall column performance. Axial dispersion alters the shape of exit breakthrough curves about the $50 \%$ breakthrough concentration level with a slight shifting of the breakthrough curve.

Mechanisms such as surface migration or adsorption kinetics are not included in the column model since their impacts were considered to be negligible or indirectly incorporated into the other features of the model during the parameter estimation process. 


\subsection{Single-Component Model}

The VERSE-LC code (Berninger et al., 1991) was used for the ion-exchange column modeling presented in this report based on its availability and previous experience with its use. VERSE-LC solves a set of equations describing one-dimensional transport along the axial dimension of an ion-exchange column coupled to one-dimensional diffusion within a porous particle representing the resin. In general, a multi-component ion-exchange model can be used in VERSE-LC to describe adsorption of species from the liquid phase onto the resin. Under certain situations, the multi-component transport equations can be decoupled into a series of single-component transport equations. The reduction to single-component equations is valid when the total ionic strength is the same in the column's local and feed solutions or is a reasonable approximation when one ion absorbs onto the resin significantly more than others. Cesium adsorption on CST can be adequately modeled using the singlecomponent approach which achieves a significant savings in computational time. In the model, we assume that kinetics associated with local ion exchange at an active resin surface site are very fast compared to the various liquid mass transfer mechanisms that transport ions to the site.

For each species, the one-dimensional (ion) transport equation in the liquid phase solved by VERSE-LC is:

$$
\begin{aligned}
& \varepsilon_{\mathrm{b}} \frac{\partial \mathrm{c}_{\mathrm{b}}}{\partial \mathrm{t}}+\varepsilon_{\mathrm{b}} \mathrm{u} \frac{\partial \mathrm{c}_{\mathrm{b}}}{\partial \mathrm{z}}=\varepsilon_{\mathrm{b}} \mathrm{E}_{\mathrm{b}} \frac{\partial^{2} \mathrm{c}_{\mathrm{b}}}{\partial \mathrm{z}^{2}}-\left(\frac{3}{<\mathrm{R}_{\mathrm{p}}>}\right)\left(1-\varepsilon_{\mathrm{b}}\right) \mathrm{k}_{\mathrm{f}}\left(\mathrm{c}_{\mathrm{b}}-\left.\mathrm{c}_{\mathrm{p}}\right|_{\mathrm{r}=\mathrm{R}_{\mathrm{p}}}\right) . \\
& \text { storage advection axial liquid film diffusion } \\
& \text { dispersion (mass transfer) }
\end{aligned}
$$

Boundary and initial conditions for Eq. (3-1a) are:

$$
\begin{array}{ll}
\mathrm{z}=0, & \mathrm{E}_{\mathrm{b}} \frac{\partial \mathrm{c}_{\mathrm{b}}}{\partial \mathrm{z}}=\mathrm{u}\left[\mathrm{c}_{\mathrm{b}}-\mathrm{c}_{\mathrm{b}}^{\text {feed }}(\mathrm{t})\right], \\
\mathrm{z}=1, & \varepsilon_{\mathrm{b}} \mathrm{E}_{\mathrm{b}} \frac{\partial \mathrm{c}_{\mathrm{b}}}{\partial \mathrm{z}}=0, \\
\mathrm{t}=0, & \mathrm{c}_{\mathrm{b}}=\mathrm{c}_{\mathrm{b}}(0, \mathrm{z}) .
\end{array}
$$

In Eqs. (3-1a) - (3.1d):

$$
\begin{aligned}
& \varepsilon_{\mathrm{b}} \ldots \ldots \ldots \ldots \ldots . . . . . . . .3 e d \text { or column porosity, } \\
& \text { u....................Interstitial fluid velocity, } \mathrm{cm} / \mathrm{min} \text {, } \\
& \mathrm{c}_{\mathrm{b}} \text {..................Ion concentration in bed fluid, } \mathrm{M} \text {, } \\
& c_{p} \text {................. Ion concentration in pore fluid, } \mathrm{M} \text {, } \\
& \mathrm{E}_{\mathrm{b}} \text {.................Axial diffusion coefficient, } \mathrm{cm}^{2} / \mathrm{min} \text {, } \\
& <\mathrm{R}_{\mathrm{p}}>\text {..........Average particle radius, } \mathrm{cm} \text {, } \\
& \mathrm{k}_{\mathrm{f}} \text {.................Liquid film mass transfer coefficient, } \mathrm{cm} / \mathrm{min} \text {, }
\end{aligned}
$$


r

Radial coordinate within average size particle, $\mathrm{cm}$,

z ...................Axial coordinate within column, cm,

t .....................Time, min.

The one-dimensional species transport equation within a resin particle pore is:

$$
\varepsilon_{\mathrm{p}} \frac{\partial \mathrm{c}_{\mathrm{p}}}{\partial \mathrm{t}}+\left(1-\varepsilon_{\mathrm{p}}\right) \overline{\mathrm{C}}_{\mathrm{T}}\left(\frac{\partial \mathrm{q}}{\partial \mathrm{c}_{\mathrm{p}}}\right) \frac{\partial \mathrm{c}_{\mathrm{p}}}{\partial \mathrm{t}}=\varepsilon_{\mathrm{p}} \mathrm{D}_{\mathrm{p}} \frac{1}{\mathrm{r}^{2}} \frac{\partial}{\partial \mathrm{r}}\left[\mathrm{r}^{2} \frac{\partial \mathrm{c}_{\mathrm{p}}}{\partial \mathrm{r}}\right]
$$

storage

surface adsorption
Fickian pore diffusion

Boundary and initial conditions for Eq. (3-2a) are:

$$
\begin{array}{ll}
\mathrm{r}=0, & \frac{\partial \mathrm{c}_{\mathrm{p}}}{\partial \mathrm{r}}=0, \\
\mathrm{r}=<\mathrm{R}_{\mathrm{p}}>, & \varepsilon_{\mathrm{p}} \mathrm{D}_{\mathrm{p}} \frac{\partial \mathrm{c}_{\mathrm{p}}}{\partial \mathrm{r}}=\mathrm{k}_{\mathrm{f}}\left(\mathrm{c}_{\mathrm{b}}-\mathrm{c}_{\mathrm{p}}\right), \\
\mathrm{t}=0, & \mathrm{c}_{\mathrm{p}}=\mathrm{c}_{\mathrm{p}}(0, \mathrm{r}) .
\end{array}
$$

In Eqs. (3-2a) - (3-2d):

$$
\begin{aligned}
& \varepsilon_{\mathrm{p}} \text {..................Particle porosity, } \\
& \overline{\mathrm{C}}_{\mathrm{T}} \text {..................Total ion-exchange capacity of resin, moles/liter bed volume, } \\
& \text { q ..................Species loading on resin, } \\
& \mathrm{D}_{\mathrm{p}} \text {................Pore diffusion coefficient, } \mathrm{cm}^{2} / \mathrm{min} \text {. }
\end{aligned}
$$

Assuming local equilibrium between the pore fluid and its neighboring surface sites, a multicomponent equilibrium isotherm model for the ion exchange between the pore liquid and solid phase can be expressed as:

$$
\mathrm{q}=f\left(\overline{\mathrm{C}}_{\mathrm{T}}, \mathrm{c}_{\mathrm{p} 1}, \mathrm{c}_{\mathrm{p} 2}, \cdots, \mathrm{c}_{\mathrm{pN}_{\mathrm{s}}}\right) \text {. }
$$

In Eq. (3-3), it is assumed that surface loading can be explicitly related to the local liquid concentrations. An example of a single-component equilibrium isotherm model for ion exchange between the pore fluid and solid phase is the Langmuir adsorption isotherm:

$$
\mathrm{q}=f(\mathrm{c})=\frac{\mathrm{C}_{\mathrm{T}} \mathrm{c}_{\mathrm{p}}}{\beta+\mathrm{c}_{\mathrm{p}}},
$$

where the $\beta$ parameter is a function of the feed conditions. 


\subsection{Cesium Isotherms}

Detailed thermodynamic models were used to generate cesium isotherm data specific for each SCIX feed composition. The isotherm data was fit to an appropriate algebraic model that could be used in VERSE-LC. The ZAM model developed at Texas A\&M University was used to generate isotherm data for CST. The ZAM code is a product of several years of development and research in Professor Anthony's Kinetics, Catalysis, and Reaction Engineering Laboratory in the Department of Chemical Engineering. A Windows based executable has been obtained for use at SRNL. No extensive user guide exists for ZAM; however, a brief user guide is available from Professor Anthony. A description of the ZAM model is provided by Zheng et al. (1997) and in Appendix E of Hamm et al. (2002).

In the column modeling, we assume that the rate of ion exchange at a surface site is very fast compared to the rates of diffusion within the pore fluid and mass transfer across the liquid film at the outer boundaries of the particles. In other words, we assume that local equilibrium exists between the pore fluid and its neighboring surface sites. With this assumption, an algebraic expression relating ionic concentrations between the pore fluid and the solid CST resin surface sites (referred to as our "isotherm model") can be developed for use in VERSE-LC column simulations. No explicit attempt has been made to verify this assumption. In an indirect manner, this assumption is either incorporated into the model parameters or verified by the comparison of model results to data. In addition, we assume that for each unique feed stream the total cesium capacity of the ion-exchange resin (active sites for cesium per gram of resin) remains independent of ionic strength and solution composition throughout the ion-exchange process.

\subsection{Isotherm Model for VERSE-LC Application}

The most general form of isotherm model we have used in VERSE-LC calculations is the Freundlich/Langmuir Hybrid model shown in Eq. (4-1):

$$
\overline{\mathrm{C}}_{\mathrm{pi}}=\frac{\mathrm{a}_{\mathrm{i}} \mathrm{c}_{\mathrm{pi}}^{\mathrm{M}_{\mathrm{i}}}}{\beta_{\mathrm{i}}+\mathrm{b}_{1} \mathrm{c}_{\mathrm{p} 1}^{\mathrm{M}_{\mathrm{b} 1}}+\mathrm{b}_{2} \mathrm{c}_{\mathrm{p} 2}^{\mathrm{M}_{\mathrm{b} 2}}+\mathrm{b}_{3} \mathrm{c}_{\mathrm{p} 3}^{\mathrm{M}_{\mathrm{b}}}+\mathrm{b}_{4} \mathrm{c}_{\mathrm{p} 4}^{\mathrm{M}_{\mathrm{b} 4}}+\mathrm{b}_{5} \mathrm{c}_{\mathrm{p} 5}^{\mathrm{M}_{\mathrm{b} 5}}} \quad \text { for } \quad \mathrm{i}=1 \ldots \mathrm{n},
$$

where

$\overline{\mathrm{C}}_{\mathrm{pi}}$..............species i solid surface concentration based on bed volume, gmole/L-BV

$\mathrm{c}_{\mathrm{pi}}$...............species $\mathrm{i}$ concentration in pore fluid, $\mathrm{M}$

$\beta_{i}, a_{i}, b_{i} \ldots . . .$. Freundlich/Langmuir Hybrid model coefficients for species $i$

$\mathrm{M}_{\mathrm{ai}}, \mathrm{M}_{\mathrm{bi}} \ldots . .$. Freundlich/Langmuir Hybrid model exponents for species $\mathrm{i}$

Adsorbing species considered in CST isotherm models are: $\mathrm{Cs}^{+}, \mathrm{Na}^{+}, \mathrm{K}^{+}, \mathrm{H}^{+}, \mathrm{Sr}^{+2}$, and $\mathrm{Rb}^{+}$. The Freundlich/Langmuir Hybrid model can be reduced to the form of an "effective" singlecomponent $\left(\mathrm{Cs}^{+}\right)$isotherm when the $\mathrm{Na}^{+}, \mathrm{K}^{+}, \mathrm{H}^{+}, \mathrm{Sr}^{+2}$, and $\mathrm{Rb}^{+}$concentrations throughout the column are assumed to be at their feed concentration levels. That is, it is assumed that 
these ions quickly reach an equilibrium with the ion-exchange resin. For an "effective" single-component cesium isotherm, Eq. (4-1) reduces to:

$$
\overline{\mathrm{C}}_{\mathrm{p} 1}=\frac{\mathrm{a}_{1} \mathrm{c}_{\mathrm{p} 1}^{\mathrm{M}_{\mathrm{a} 1}}}{\left[\beta_{\mathrm{i}}+\mathrm{b}_{2} \mathrm{c}_{\mathrm{p} 2}^{\mathrm{M}_{\mathrm{b} 2}}+\mathrm{b}_{3} \mathrm{c}_{\mathrm{p} 3}^{\mathrm{M}_{\mathrm{b} 3}}+\mathrm{b}_{4} \mathrm{c}_{\mathrm{p} 4}^{\mathrm{M}_{\mathrm{b} 4}}+\mathrm{b}_{4} \mathrm{c}_{\mathrm{p} 5}^{\mathrm{M}_{\mathrm{b} 5}}\right]+\mathrm{b}_{1} \mathrm{c}_{\mathrm{p} 1}^{\mathrm{M}_{\mathrm{b} 1}}} \Rightarrow \frac{\mathrm{a}_{1} \mathrm{c}_{\mathrm{p} 1}^{\mathrm{M}_{\mathrm{a}}}}{\hat{\beta}_{1}+\mathrm{b}_{1} \mathrm{c}_{\mathrm{p} 1}^{\mathrm{M}_{\mathrm{b} 1}}},
$$

where $\hat{\beta}_{1}$ is the Freundlich/Langmuir "effective" single-component isotherm constant for cesium. The beta parameter for cesium is then dependent upon the $\mathrm{Na}^{+}, \mathrm{K}^{+}, \mathrm{H}^{+}, \mathrm{Sr}^{+2}$, and $\mathrm{Rb}^{+}$feed concentrations. Without loss of generality, we can divide the numerator and denominator of Eq. (4-2) by $b_{1}$ to obtain:

$$
\overline{\mathrm{C}}_{\mathrm{p} 1}=\frac{\mathrm{a}_{1}^{\prime} \mathrm{c}_{\mathrm{p} 1}^{\mathrm{M}_{\mathrm{a}}}}{\beta_{1}^{\prime}+\mathrm{c}_{\mathrm{p} 1}^{\mathrm{M}_{\mathrm{b} 1}}}
$$

Equation (4-3) uses the resin capacity expressed in terms of mmol per liter of bed volume whereas the resin capacity $\mathrm{Q}_{\mathrm{Cs}}$ is typically calculated as mmol per gram resin. The VERSELC isotherm coefficient $\mathrm{a}_{1}^{\prime}$ in Eq. (4-3) is therefore computed as:

$$
\mathrm{a}_{1}^{\prime}=\rho_{\mathrm{b}} \eta_{\mathrm{df}} \overline{\mathrm{C}}_{\mathrm{T}}
$$

where $\rho_{\mathrm{b}}$ is the bed density of the active column in $\mathrm{g} / \mathrm{ml}$ and $\eta_{\mathrm{df}}$ is a resin degradation factor that can be used to lower the total capacity to account for the effects of chemical or radioactive exposure. The final form of the isotherm model as used in VERSE-LC is then:

$$
\overline{\mathrm{C}}_{\mathrm{pCs}}=\eta_{\mathrm{df}}\left[\frac{\rho_{\mathrm{b}} \overline{\mathrm{C}}_{\mathrm{T}} \mathrm{c}_{\mathrm{pCs}}^{\mathrm{M}_{\mathrm{aCs}}}}{\beta_{\mathrm{Cs}}+\mathrm{c}_{\mathrm{pCs}}^{\mathrm{M}_{\mathrm{bCs}}}}\right],
$$

where the prime on $\beta$ is dropped to simplify the notation. The composite impact on cesium loading from the competitor cations is summed up in the $\beta_{\text {Cs }}$ parameter as shown above in Eq. (4-5). The degradation factor, $\eta_{\mathrm{df}}$, is set to unity for fresh resin and less than unity to account for resin aging effects. The CST cesium adsorption isotherm used in this study is the Langmuir form of Eq. (4-5):

$$
Q=\frac{a[C s]}{\beta+[C s]}
$$

where $Q$ is cesium loading on the CST media in moles/liter bed volume, [Cs] is the total molar cesium concentration in solution, and the isotherm parameters $a$ and $\beta$ are calculated using the ZAM code. As described by Aleman (2003), the CST total capacity calculated by ZAM (parameter $a$ ) was multiplied by a factor of 0.68 to account for the difference between CST powder and the engineered form of the material. 


\subsection{Column Properties}

Certain material properties such as resin density and total ionic capacity are unique to the ion-exchange material and vary only between batches. On the other hand, composite properties associated with an ion-exchange column such as bed density and porosity are inherently column specific. Even when different columns are made from the same batch of resin, column properties may vary. The discussion that follows focuses on the column properties required to perform transport simulations.

\subsection{Basic Constraint Functions}

Based on geometrical considerations, not all densities and porosities are independent. The following two expressions place constraints on the porosities and densities:

$$
\varepsilon_{\mathrm{t}}=\varepsilon_{\mathrm{b}}+\left(1-\varepsilon_{\mathrm{b}}\right) \varepsilon_{\mathrm{p}}
$$

and

$$
\rho_{\mathrm{b}}=\rho_{\mathrm{s}}\left(1-\varepsilon_{\mathrm{t}}\right)=\rho_{\mathrm{s}}\left(1-\varepsilon_{\mathrm{b}}\right)\left(1-\varepsilon_{\mathrm{p}}\right)
$$

where

$\varepsilon_{\mathrm{t}}$ …..............total porosity of column,

$\varepsilon_{\mathrm{b}} \ldots \ldots \ldots \ldots \ldots . . . . . . . .6 \mathrm{bed}$ porosity of column,

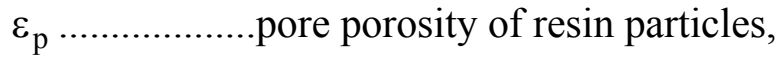

$\rho_{\mathrm{b}} \ldots \ldots . . . . . . . . . . . .$. bed density of active column, $\mathrm{g} / \mathrm{ml}$,

$\rho_{\mathrm{s}} \ldots \ldots \ldots \ldots . . . . . . .$. solid (particle) density of resin, $\mathrm{g} / \mathrm{ml}$.

For the five variables listed above, only three are independent. The various porosities used in Eq. (5-1) are defined as:

$$
\varepsilon_{\mathrm{b}}=\frac{\mathrm{V}_{\text {void }}-\mathrm{V}_{\text {pore }}}{\mathrm{V}_{\text {bed }}} ; \quad \varepsilon_{\mathrm{p}}=\frac{\mathrm{V}_{\text {pore }}}{\mathrm{V}_{\text {part }}} ; \quad \varepsilon_{\mathrm{t}}=\frac{\mathrm{V}_{\text {void }}}{\mathrm{V}_{\text {bed }}}=\frac{\mathrm{V}_{\text {bed }}-\mathrm{V}_{\text {sld }}}{\mathrm{V}_{\text {bed }}}
$$

where

$$
\begin{aligned}
& \mathrm{V}_{\text {bed }} \text {...............total volume of active (bed) column, ml, } \\
& \mathrm{V}_{\text {void }} \text {..............total volume of voids within active column, } \mathrm{ml} \text {, } \\
& \mathrm{V}_{\text {pore }} \text {..............total volume of pores within particles, } \mathrm{ml} \text {, } \\
& \mathrm{V}_{\text {part }} \text {...............total volume of particles within active column, } \mathrm{ml} \text {, } \\
& \mathrm{V}_{\text {sld }} \text {................total volume of solid resin within active column, } \mathrm{ml} \text {. }
\end{aligned}
$$




\subsection{CST Media Properties}

CST physical parameters are the same as those used in previous studies performed by Aleman (2003) and Smith (2007):

Particle radius $-172 \mu \mathrm{m}$

Particle void fraction -0.24

Bed void fraction -0.50

Bed density $-1.0 \mathrm{~kg}$ CST media/liter bed volume

The bed void listed above may be somewhat high or, equivalently, the bed density may be somewhat low. These values are conservative for estimating the number of columns required to process the salt solution but will be non-conservative for estimating the total cesium loading used in thermal analysis and dose rates of the column. Lower bed void would increase the bed density leaving the overall mass of CST required to process the dissolved salt cake unchanged. However, lower bed void and the corresponding higher bed density will increase the cesium loading capacity in a single column. The void fractions and bed density give a CST solid density of $2.63 \mathrm{~g} / \mathrm{ml}$. 


\subsection{Solution Properties and Pore Diffusion}

\subsection{Molecular Diffusion Coefficients}

Molecular diffusion coefficients are important in determining key dimensionless numbers (e.g., Schmidt Number, Sc) used in various constitutive law correlations for column transport modeling. They also provide an upper bound for pore diffusion coefficients. Binary, sometimes referred to as free stream, diffusion coefficients of electrolytes originating from a single salt in solution under dilute conditions can be reasonably estimated using the Nernst-Haskell equation (Reid et al., 1977):

$$
\mathrm{D}_{ \pm}^{\infty}=\left(\frac{\mathrm{RT}}{F^{2}}\right)\left[\frac{\frac{1}{\mathrm{z}_{+}}+\frac{1}{\mathrm{z}_{-}}}{\frac{1}{\lambda_{+}^{\mathrm{o}}}+\frac{1}{\lambda_{-}^{\mathrm{o}}}}\right],
$$

where

$$
\begin{aligned}
& \mathrm{D}_{ \pm}^{\infty} \ldots \ldots \ldots . . . . . \text { binary diffusion coefficient at infinite dilution, } \mathrm{cm}^{2} / \mathrm{s} \\
& \lambda_{+}^{0}, \lambda_{-}^{0} \ldots . . . . . . . . \text { limiting ionic conductivity for cation and anion pair, mhos/equivalent } \\
& \mathrm{z}_{+}, \mathrm{z}_{-} \ldots \ldots . . . . . \text { valences of cation and anion pair, respectively } \\
& \text { F ...........Faraday constant, 96,500 C/g-equivalent } \\
& \mathrm{R} \text {............gas constant, } 8.314 \mathrm{~J} / \text { gmole-K } \\
& \mathrm{T} \text {............absolute temperature, } \mathrm{K}
\end{aligned}
$$

Limiting ionic conductivities at $25^{\circ} \mathrm{C}$ and infinite dilution for the various ions of interest in this study are tabulated in Table 6-1. Most of the conductivities were calculated using the correlation shown in Eq. (6-2) from Anderko and Lencka (1997):

$$
\ln \left[\lambda^{0}(\mathrm{~T}) \eta(\mathrm{T})\right]=\mathrm{A}+\mathrm{B} / \mathrm{T}
$$

where

A, B............correlation coefficients

$\eta(\mathrm{T}) \ldots \ldots . . . . .$. viscosity of pure water in Pa-s $(\mathrm{cP} / 1000)$

The correlation coefficients A and B are listed in Table 6-1. In a few instances, where the anion was not included in the Anderko correlation, literature values of the ionic conductivity (Reid et al., 1977; Perry, 1973; Glasstone and Lewis, 1960) were used.

Using Eq. (6-1) and the limiting ionic conductivities provided in Table 6-1, the binary molecular diffusion coefficient for single salts within an aqueous phase can be computed. To account for fluid property differences between a salt solution and pure water, a correction factor is applied. Based on hydrodynamic theory, the following expression, typically referred to as the Stokes-Einstein equation, is obtained (Bird et al., 1960, page 514): 


$$
\frac{\mathrm{D}_{\mathrm{AB}} \mu_{\mathrm{B}}}{\kappa \mathrm{T}}=\frac{1}{6 \pi \mathrm{R}_{\mathrm{A}}},
$$

where

$$
\begin{aligned}
& \mathrm{D}_{\mathrm{AB}} \text { ….........binary diffusion coefficient for A diffusing through solvent } \mathrm{B} \text {, } \\
& \mu_{B} \text {............dynamic viscosity of solvent mixture, } \\
& \mathrm{R}_{\mathrm{A}} \text { …......... radius of diffusing particle, } \\
& \text { К ............Boltzmann's constant. }
\end{aligned}
$$

Based on Eq. (6-3), the ratio of the dynamic viscosity of pure water (representing conditions at infinite dilution) to that of the salt solution is a correction factor that can be applied to the molecular diffusion coefficients computed using Eq. (6-1) to estimate binary diffusion coefficients in the salt solution. An overall diffusion coefficient for cesium was calculated as the average of the individual cesium-anion pair diffusion coefficients weighted by the mole fraction of each anion in solution. Cesium diffusion coefficients calculated using this method for the feed solutions used in this study are listed in Table 6-2.

\subsection{Waste Solution Density and Viscosity}

Two other physical properties needed for VERSE-LC simulations are the density and viscosity of the bulk liquid phase. Dissolved salt solution density and viscosity vary as functions of temperature and composition. The density and viscosity of the feed solutions used in the VERSE-LC calculations were computed using OLI Systems, Inc. Analyzer Studio $^{\mathrm{TM}}$ Version 3.1. The solution density and viscosity calculated for the six feed solutions at the three temperatures of interest are listed in Table 6-2.

\subsection{Particle Kinetics Parameters}

The rate of cesium uptake controls the transient behavior of the column. As the rate of cesium uptake by the resin is increased, the breakthrough curve becomes sharper (steeper) and utilization of the resin is increased. Thus, accurate evaluation of the parameters that control the rate of cesium uptake is essential for modeling column performance. We assume that the rate of chemical adsorption (i.e. exchange of ions at a surface site) is very fast when compared to the rates of diffusion within the pore fluid and mass transfer across the liquid film at the outer boundary of the particles. Hence, within the resin particles, the rate of cesium uptake is dominated by intra-particle diffusion. Diffusion within the particles is governed by the pore diffusivity, particle porosity, and size of the particles. Externally, the rate of cesium transport from the inter-particle fluid to the particle surface depends upon the film mass transfer coefficient. Due to their influence on the rate of cesium uptake and, thus, the transient behavior of the column, the particle porosity, pore diffusivity, particle radius, and the film mass transfer coefficient are referred to as kinetics parameters.

As shown in Section 7, in VERSE-LC the film mass transfer coefficient is calculated from a correlation developed by Wilson and Geankoplis (1966). Particle porosity is available from the data presented in Section 5. Therefore, of the kinetics parameters, the pore diffusivity, and diffusion length remain to be determined. In the VERSE-LC code, the model for intra- 
particle diffusion assumes that the particles are spheres of uniform radius. To apply the VERSE-LC model it is therefore necessary to determine an average radius from the particle size distribution and an effective pore diffusivity.

We assume that the pore sizes are large relative to the size of the migrating ions of interest and that pore diffusion coefficients should not be significantly lower than their bulk or free stream values. However, some level of reduced diffusion in the pores is expected resulting from bends along the pore paths that are generally accounted for by a particle tortuosity factor $\tau$ defined as:

$$
\mathrm{D}_{\mathrm{p}}=\frac{\mathrm{D}_{\infty}}{\tau}
$$

In Eq. (6-4), $\mathrm{D}_{\mathrm{p}}$ is the diffusivity of $\mathrm{Cs}^{+}$in the particle pore and $\mathrm{D}_{\infty}$ is the bulk diffusivity of $\mathrm{Cs}^{+}$in the free stream. Tortuosity factors for CST were determined by analyzing experimental data obtained at SRNL (Hamm et al., 2002). In these studies, it was found that using $\tau=5$ (i.e. $\mathrm{D}_{\mathrm{p}}=0.2 \mathrm{D}_{\infty}$ ) gave reasonable predictions of experimental data.

Table 6-1. Limiting ionic conductivity fitting coefficients and calculated conductivities in water at $25^{\circ} \mathrm{C}$.

\begin{tabular}{|c|c|c|c|c|c|}
\hline \multicolumn{2}{|c|}{ Ion } & $\begin{array}{c}\text { Ionic } \\
\text { Valance }\end{array}$ & A & B & $\begin{array}{c}\text { Limiting ionic } \\
\text { conductivity } \\
\text { MHOS/equivalent }\end{array}$ \\
\hline \hline \multirow{4}{*}{ Cations } & $\mathrm{H}^{+}$ & 1 & -3.9726 & 837.79 & 351.05 \\
\cline { 2 - 6 } & $\mathrm{Na}^{+}$ & 1 & -3.3594 & 75.492 & 50.27 \\
\cline { 2 - 6 } & $\mathrm{K}^{+}$ & 1 & -3.5730 & 254.36 & 73.97 \\
\cline { 2 - 6 } & $\mathrm{Rb}^{+}$ & 1 & -3.6517 & 294.79 & 78.34 \\
\cline { 2 - 6 } & $\mathrm{Cs}^{+}$ & 1 & -3.6512 & 291.42 & 77.46 \\
\hline \hline \multirow{7}{*}{ Anions } & $\mathrm{OH}^{-}$ & -1 & -3.3346 & 468.13 & 192.30 \\
\cline { 2 - 6 } & $\mathrm{NO}_{3}^{-}$ & -1 & -3.6743 & 277.43 & 72.22 \\
\cline { 2 - 6 } & $\mathrm{NO}_{2}^{-}$ & -1 & & & $72.00^{\mathrm{b}}$ \\
\cline { 2 - 6 } & $\mathrm{F}^{-}$ & -1 & & & $55.40^{\mathrm{b}}$ \\
\cline { 2 - 6 } & $\mathrm{Cl}^{-}$ & -1 & -3.4051 & 216.03 & 76.94 \\
\cline { 2 - 6 } & $\mathrm{I}^{-}$ & -1 & -3.5660 & 265.28 & 77.27 \\
\cline { 2 - 6 } & $\mathrm{CO}_{3}^{-2}$ & -2 & & & $69.30^{\mathrm{b}}$ \\
\cline { 2 - 6 } & $\mathrm{SO}_{4}^{-2}$ & -2 & -2.9457 & 90.983 & 75.08 \\
\cline { 2 - 6 } & $\mathrm{PO}_{4}^{-2}$ & -2 & & & $70.00^{\mathrm{a}}$ \\
\cline { 2 - 6 } & ${\mathrm{Al}(\mathrm{OH})_{4}^{-}}^{-2}$ & -1 & & & \\
\hline
\end{tabular}

${ }^{\mathrm{a}}$ Estimated value, ${ }^{\mathrm{b}}$ Literature value 
Table 6-2. Feed solution physical properties.

\begin{tabular}{|c|c|c|c|c|c|}
\hline & Batch & $\begin{array}{c}\text { Temperature } \\
\text { (C) }\end{array}$ & $\begin{array}{c}\text { Density } \\
(\mathrm{g} / \mathrm{ml})\end{array}$ & $\begin{array}{l}\text { Viscosity } \\
\text { (Poise) }\end{array}$ & $\begin{array}{c}\text { Cs } D_{\infty} \\
\left(\mathrm{cm}^{2} / \mathrm{min}\right)\end{array}$ \\
\hline \multirow{12}{*}{$\begin{array}{c}\text { With } \\
\text { Caustic } \\
\text { Additio } \\
\text { n }\end{array}$} & \multirow{3}{*}{1} & 25 & 1.248 & 0.0343 & $3.83 \mathrm{E}-04$ \\
\hline & & 35 & 1.241 & 0.0258 & $4.26 \mathrm{E}-04$ \\
\hline & & 45 & 1.234 & 0.0203 & 4.63E-04 \\
\hline & \multirow{3}{*}{2} & 25 & 1.241 & 0.0331 & $4.05 \mathrm{E}-04$ \\
\hline & & 35 & 1.234 & 0.0247 & $4.53 \mathrm{E}-04$ \\
\hline & & 45 & 1.227 & 0.0193 & $4.95 \mathrm{E}-04$ \\
\hline & \multirow{3}{*}{3} & 25 & 1.233 & 0.0271 & 4.73E-04 \\
\hline & & 35 & 1.227 & 0.0208 & $5.16 \mathrm{E}-04$ \\
\hline & & 45 & 1.220 & 0.0165 & $5.54 \mathrm{E}-04$ \\
\hline & \multirow{3}{*}{4} & 25 & 1.228 & 0.0294 & 4.52E-04 \\
\hline & & 35 & 1.222 & 0.0223 & 4.97E-04 \\
\hline & & 45 & 1.215 & 0.0176 & $5.38 \mathrm{E}-04$ \\
\hline \multirow{6}{*}{$\begin{array}{c}\text { Without } \\
\text { Caustic } \\
\text { Additio } \\
\text { n }\end{array}$} & \multirow{3}{*}{$1 x$} & 25 & 1.238 & 0.0307 & $4.18 \mathrm{E}-04$ \\
\hline & & 35 & 1.231 & 0.0234 & $4.58 \mathrm{E}-04$ \\
\hline & & 45 & 1.224 & 0.0186 & 4.93E-04 \\
\hline & \multirow{3}{*}{$2 x$} & 25 & 1.231 & 0.0296 & 4.44E-04 \\
\hline & & 35 & 1.224 & 0.0224 & 4.90E-04 \\
\hline & & 45 & 1.217 & 0.0177 & $5.30 \mathrm{E}-04$ \\
\hline
\end{tabular}




\subsection{Film Diffusion and Axial Dispersion}

In this section, we present the correlations used to define: (1) mass transfer across the liquid film separating the bed fluid from its neighboring particle pore fluid and (2) axial dispersion along the bed length.

\subsection{Film Diffusion}

For laboratory-scale column tests and the proposed full-scale facility, the range of flow Reynolds number is approximately 0.1 to 1.0 . With respect to published literature, this is a very low Reynolds number range. Numerous mass transfer correlations exist as discussed by Foo and Rice (1975). One of the correlations compared in Foo and Rice (1975) is the one developed by Wilson and Geankoplis (1966) based on low Reynolds number data. Large variations between correlations exist; however, the sensitivity of VERSE-LC results to the film coefficient is typically low. VERSE-LC has the Wilson and Geankoplis correlation as an option and this correlation falls within the spread of available low Reynolds number data. Therefore, we have chosen to use it for the column simulations in this report. For each ion species considered, the Wilson and Geankoplis correlation is expressed as:

$$
\mathrm{J} \equiv\left[\frac{\mathrm{k}_{\mathrm{fi}}}{\mathrm{u} \varepsilon_{\mathrm{b}}}\right] \mathrm{Sc}_{\mathrm{i}}^{2 / 3}=\frac{1.09}{\varepsilon_{\mathrm{b}}} \mathrm{Re}^{-2 / 3}
$$

In Eq. (7-1), the Reynolds number is defined as:

$$
\operatorname{Re} \equiv \frac{2 \mathrm{R}_{\mathrm{p}} \rho_{\mathrm{w}} \mathrm{u} \varepsilon_{\mathrm{b}}}{\mu_{\mathrm{w}}},
$$

and the Schmidt number for each species is defined as:

$$
\mathrm{Sc}_{\mathrm{i}} \equiv \frac{\mu_{\mathrm{w}}}{\rho_{\mathrm{w}} \mathrm{D}_{\mathrm{i}}^{\infty}}
$$

A standard deviation of approximately $25 \%$ is reported for Eq. (7-1) by Wilson and Geankoplis (1966), while from comparison to the various correlations presented by Foo and Rice (1975) a standard deviation of $100 \%$ to $200 \%$ is observed.

\subsection{Axial Dispersion}

Axial dispersion in packed columns is the result of mechanical dispersion added onto molecular diffusion. At practical flow rates, mechanical dispersion dominates. For wellpacked columns of sufficient diameter such that wall effects (channeling) are minimal, a variety of correlations exist for long column performance. A brief discussion of minimum column sizing is presented in Brooks (1994). 
In the low Reynolds number range of interest, the Chung and Wen (1968) correlation is applicable for sufficiently large columns (large diameter and length). The axial dispersion coefficient $\mathrm{E}_{\mathrm{b}}\left(\mathrm{cm}^{2} / \mathrm{min}\right)$ is expressed as:

$$
\mathrm{E}_{\mathrm{b}}=\frac{2 \mathrm{R}_{\mathrm{p}} \mathrm{u} \varepsilon_{\mathrm{b}}}{0.2+0.011 \mathrm{Re}^{0.48}}
$$

The standard deviation of this correlation based on all available data points was reported to be $46 \%$. Equation (7-2) applies for sufficiently large columns and correction factors must be considered for columns with small diameters and/or short active bed lengths. This correlation is applied for the column simulations in this report. 


\subsection{Column Performance Case Studies}

A matrix showing the pattern of feed flows and temperatures tested in this study is provided in Table 8-1. These five case studies were run for each of the six tank compositions used in this study for a total of 30 column simulations. All of the column simulations assumed a single column length of 15 feet and two columns (lead and lag) placed in series. Using a column length of 15 feet gives a single column bed volume of 427.6 gallons.

- Case 1 represents nominal operating conditions.

- Case 2 is operation at lower flow, which sharpens the breakthrough curve and allows more salt solution to be processed during each cycle at the expense of longer operating times.

- Case 3 is operation at higher flow, which spreads out the breakthrough curve and decreases the amount of salt solution that can be processed during each cycle with a corresponding savings in operating time.

- Case 4 is operation at lower temperature which increases the ion-exchange capacity.

- Case 5 is operation at elevated temperature which reduces overall ion-exchange capacity.

Table 8-1. VERSE-LC case study matrix of feed flows and column temperatures.

\begin{tabular}{|c|c||c|c|c|}
\hline \multicolumn{2}{|c||}{$\begin{array}{c}\text { Case Run } \\
\text { Matrix }\end{array}$} & \multicolumn{3}{c|}{ Temperature (C) } \\
\cline { 2 - 5 } & $\mathbf{2 5}$ & $\mathbf{3 5}^{1}$ & $\mathbf{4 5}$ \\
\hline \hline \multirow{2}{*}{$\begin{array}{c}\text { Feed } \\
\text { Flow } \\
\text { (gpm) }\end{array}$} & $\mathbf{5}$ & & 2 & \\
\cline { 2 - 5 } & $\mathbf{1 0}$ & 4 & 1 & 5 \\
\cline { 2 - 5 } & $\mathbf{2 0}$ & & 3 & \\
\hline
\end{tabular}

${ }^{1}$ Nominal values 


\subsection{Modeling Results}

\subsection{CST Isotherm Parameters}

Cesium isotherms for CST were generated for each feed composition and temperature by varying the cesium concentration over a range from $1.0 \times 10^{-9} \mathrm{M}$ to $0.1 \mathrm{M}$ and using the ZAM code to calculate the equilibrium cesium loading on the CST and corresponding equilibrium concentration in the liquid phase. These values were plotted and fit to Equation (4-6) to obtain best estimate values for parameters $a$ and $\beta$. Table 9-1 provides a list of isotherm parameters used in the VERSE-LC model for the CST column calculations for each of the SCIX feed compositions tested. In the second column of Table 9-1, the feed concentrations of total cesium in molarity and Cs-137 in $\mathrm{pCi} / \mathrm{ml}$ are listed along with the batch number. For these calculations, we have assumed that Cs-137 is 25 mole $\%$ of the total cesium in the feed. The fourth and fifth columns of Table 9-1 list the isotherm parameters. All of the ZAM calculations gave essentially the same value for parameter $a$ which is a measure of the total CST capacity. The resin capacity used in the column calculations was taken to be $68 \%$ of the nominal ZAM calculated value to account for a reduction in available capacity in going from CST particles to the engineered form. Because all of these values fell between 0.3942 and 0.3946 with an average value of 0.3944 , it was decided to use the average value for all column simulations. The sixth and seventh columns in the table show the total cesium loading on the CST media at equilibrium (Q) and the corresponding curies per liter of packed bed volume (BV). That is, these columns show the cesium loading in a fully loaded column. Since the lead column is typically very close to being fully loaded during column processing, the curie loadings reported in column six of Table 9-1 provide an estimate of the maximum heat load on the lead column for thermal analysis. As shown below, at nominal operating conditions, the lag column is loaded to between $20 \%$ and $40 \%$ of maximum capacity at the end of an ion-exchange cycle.

The sensitivity of the cesium adsorption isotherms to strontium and rubidium was investigated. For these SCIX feed compositions, the ZAM model predicted essentially no strontium adsorption on CST. Rubidium is predicted to adsorb but, at the nominal concentrations given in Table 2-1, has a relatively small impact on cesium adsorption. On average, at $35{ }^{\circ} \mathrm{C}$, increasing the rubidium concentration by a factor of 10 decreased the maximum cesium loading by $3 \%$ while decreasing the rubidium concentration by a factor of 10 increased the maximum cesium loading by less than $0.5 \%$.

The maximum cesium loadings for each SCIX feed listed in columns six and seven of Table 9-1 were calculated using a nominal bed density of $1.0 \mathrm{~g}$ resin $/ \mathrm{ml} \mathrm{BV}$ while values of the bed density ranging from 0.9 to 1.13 are estimated by Hamm et al., (2002). The nominal bed density corresponds to a bed void fraction of 0.5 which is at the high end of projected values. The highest estimated curie loading is $554 \mathrm{Ci} /($ Liter BV) for SCIX Batch 2 without caustic addition at $25{ }^{\circ} \mathrm{C}$. The lowest curie loading is $198 \mathrm{Ci} /($ Liter BV) for SCIX Batch 3 at $45{ }^{\circ} \mathrm{C}$. At the nominal operating temperature of $35^{\circ} \mathrm{C}$, cesium loadings range from 236 to $489 \mathrm{Ci} /($ Liter BV). The highest curie loading estimated in the $2007 \mathrm{SCIX}$ modeling study (Smith, 2007) was $257 \mathrm{Ci} /($ Liter BV) which was $115 \%$ of the nominal highest loading to 
account for the possibility of higher bed density. The SCIX feed compositions in the present study lead to significantly increased cesium loadings primarily because of the increased hydroxide concentrations.

Table 9-1. CST isotherm parameters.

\begin{tabular}{|c|c|c|c|c|c|c|}
\hline & $\begin{array}{c}\text { Batch \# } \\
\text { Total [Cs] } \\
\text { [Cs-137] }\end{array}$ & $\begin{array}{c}\text { Temp, } \\
\text { C }\end{array}$ & $a$ & $\beta$ & $\begin{array}{c}\mathbf{Q}, \\
\text { moles } \\
\text { Cs/L BV }\end{array}$ & $\begin{array}{c}\text { Q, } \\
\text { Ci Cs/ } \\
\text { L BV }\end{array}$ \\
\hline \multirow{12}{*}{$\begin{array}{c}\text { With } \\
\text { Caustic } \\
\text { Addition }\end{array}$} & \multirow{3}{*}{$\begin{array}{c}1 \\
1.82 \times 10^{-4} \mathrm{M} \\
5.44 \times 10^{8} \mathrm{pCi} / \mathrm{ml}\end{array}$} & 25 & 0.3944 & $2.35 \times 10^{-4}$ & 0.172 & 514.0 \\
\hline & & 35 & 0.3944 & $3.01 \times 10^{-4}$ & 0.149 & 444.2 \\
\hline & & 45 & 0.3944 & $3.83 \times 10^{-4}$ & 0.127 & 379.8 \\
\hline & \multirow{3}{*}{$\begin{array}{c}\mathbf{2} \\
2.02 \times 10^{-4} \mathrm{M} \\
6.02 \times 10^{8} \mathrm{pCi} / \mathrm{ml}\end{array}$} & 25 & 0.3944 & $2.39 \times 10^{-4}$ & 0.181 & 538.9 \\
\hline & & 35 & 0.3944 & $2.98 \times 10^{-4}$ & 0.159 & 475.1 \\
\hline & & 45 & 0.3944 & $3.72 \times 10^{-4}$ & 0.139 & 413.9 \\
\hline & \multirow{3}{*}{$\begin{array}{c}\mathbf{3} \\
9.57 \times 10^{-5} \mathrm{M} \\
2.85 \times 10^{8} \mathrm{pCi} / \mathrm{ml}\end{array}$} & 25 & 0.3944 & $3.06 \times 10^{-4}$ & 0.094 & 280.4 \\
\hline & & 35 & 0.3944 & $3.80 \times 10^{-4}$ & 0.079 & 236.5 \\
\hline & & 45 & 0.3944 & $4.74 \times 10^{-4}$ & 0.066 & 197.7 \\
\hline & \multirow{3}{*}{$\begin{array}{c}4 \\
1.73 \times 10^{-4} \mathrm{M} \\
5.15 \times 10^{8} \mathrm{pCi} / \mathrm{ml}\end{array}$} & 25 & 0.3944 & $2.55 \times 10^{-4}$ & 0.159 & 475.4 \\
\hline & & 35 & 0.3944 & $3.14 \times 10^{-4}$ & 0.140 & 417.0 \\
\hline & & 45 & 0.3944 & $3.89 \times 10^{-4}$ & 0.121 & 361.6 \\
\hline \multirow{6}{*}{$\begin{array}{l}\text { Without } \\
\text { Caustic } \\
\text { Addition }\end{array}$} & \multirow{3}{*}{$\begin{array}{c}\mathbf{1 x} \\
1.89 \times 10^{-4} \mathrm{M} \\
5.63 \times 10^{8} \mathrm{pCi} / \mathrm{ml}\end{array}$} & 25 & 0.3944 & $2.37 \times 10^{-4}$ & 0.175 & 521.6 \\
\hline & & 35 & 0.3944 & $3.03 \times 10^{-4}$ & 0.152 & 451.7 \\
\hline & & 45 & 0.3944 & $3.85 \times 10^{-4}$ & 0.130 & 386.6 \\
\hline & \multirow{3}{*}{$\begin{array}{c}\mathbf{2 x} \\
2.09 \times 10^{-4} \mathrm{M} \\
6.23 \times 10^{8} \mathrm{pCi} / \mathrm{ml}\end{array}$} & 25 & 0.3944 & $2.34 \times 10^{-4}$ & 0.186 & 554.5 \\
\hline & & 35 & 0.3944 & $2.94 \times 10^{-4}$ & 0.164 & 488.8 \\
\hline & & 45 & 0.3944 & $3.68 \times 10^{-4}$ & 0.143 & 425.7 \\
\hline
\end{tabular}




\subsection{Model Verification}

The ZAM isotherm model had difficulty converging for the high sodium and high hydroxide SCIX batch feed compositions used in this study. Nevertheless, full isotherm curves were generated for all of the feed compositions at the three temperatures specified except for Batches 1 and 2 at $45^{\circ} \mathrm{C}$ for which only partial isotherm curves were obtained. However, in all cases, the isotherms covered the range of cesium concentrations from the feed concentration and lower. Figure 9-1 shows a typical cesium isotherm. The circle point was obtained from ZAM using the feed cesium concentration while the triangles were obtained by varying the cesium concentration over a wide range. The line through the points is the isotherm fit to Eq. (4-6). Despite the ZAM convergence problems, the resulting cesium isotherm is a smooth curve which fits the Langmuir isotherm very closely. Similar results were obtained for all of the SCIX feed compositions.

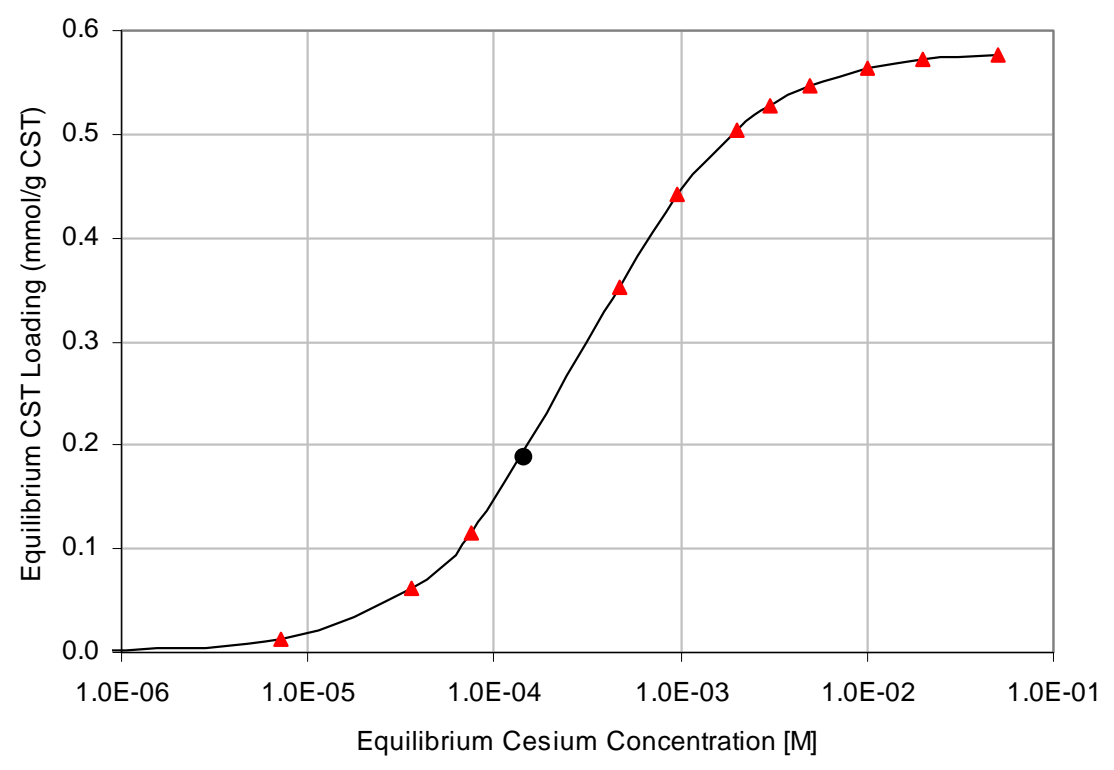

Figure 9-1. Cesium isotherm for SCIX Feed Batch 1 at $35^{\circ} \mathrm{C}$.

The ZAM results predicted relatively high cesium loadings on the CST. To verify that these predictions were reasonable, a ZAM isotherm was generated and VERSE-LC modeling performed to simulate a small column experiment conducted by Walker et al. (1999). The experiment measured the cesium breakthrough curve from a $10 \mathrm{~cm}$ CST column fed with a sample of actual SRS Tank 44 waste solution. The composition of this sample is shown in Table 9-2. While the sodium concentration is lower than the SCIX feed compositions, the hydroxide concentration is higher than that in the SCIX feeds and the ratios of $\mathrm{OH}^{-}$to $\mathrm{Na}^{+}$ and $\mathrm{OH}^{-}$to $\mathrm{NO}_{3}{ }^{-}$are much higher in the Tank 44 sample than in the SCIX feed. For this feed composition, ZAM predicted a maximum cesium loading of $742.6 \mathrm{Ci} /(\mathrm{Liter} \mathrm{BV})$ which is a higher loading than obtained for any of the SCIX feeds. 
Figure 9-2 shows a comparison between a VERSE-LC prediction of the small column experiment (solid line) and the measured breakthrough curve (points). Falling above the data, the modeling predicts slightly less CST loading than actually observed and therefore gives a somewhat conservative prediction of the breakthrough curve. The good comparison between the ZAM/VERSE modeling and this experimental data provides confidence that the SCIX feed modeling will also be reasonably accurate.

Table 9-2. Tank 44 sample composition in molarity.

\begin{tabular}{|c|c|c|c|}
\hline Anions & SRS Tank 44 & Cations & SRS Tank 44 \\
\hline $\mathrm{NO}_{2}^{-1}$ & 0.35 & $\mathrm{Na}^{+1}$ & 5.4 \\
\hline $\mathrm{NO}_{3}^{-1}$ & 0.37 & $\mathrm{~K}^{+1}$ & 0.051 \\
\hline $\mathrm{OH}^{-1}$ & 4.3 & $\mathrm{Cs}^{+1}$ & $3.51 \times 10^{-4}$ \\
\hline $\mathrm{Al}(\mathrm{OH})_{4}{ }^{-1}$ & 0.126 & & \\
\hline $\mathrm{CO}_{3}^{-2}$ & 0.1412 & & \\
\hline $\mathrm{SO}_{4}^{-2}$ & 0.001 & & \\
\hline $\mathrm{PO}_{4}^{-3}$ & 0.0001 & & \\
\hline $\mathrm{Cl}^{-1}$ & 0.009 & & \\
\hline
\end{tabular}

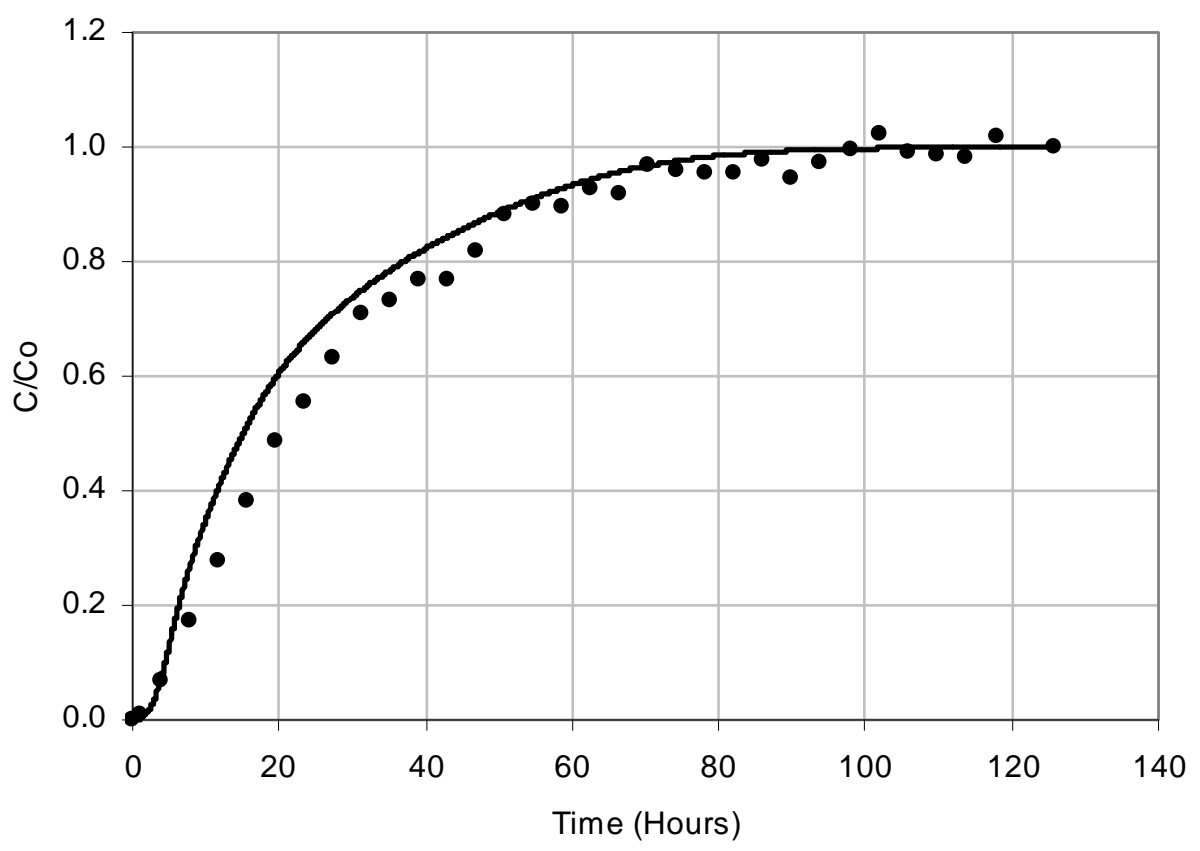

Figure 9-2. Cesium breakthrough data for CST IE-911 with actual SRS Tank 44 waste (Walker et al., 1999) and ZAM/VERSE-LC model prediction. 


\subsection{CST Ion-exchange Column Modeling Results}

Table 9-3 summarizes the results from VERSE-LC modeling of cesium removal from SCIX feeds using CST. All of the calculations assume a two-column lead-lag configuration. The results shown in Table 9-3 were obtained with fresh CST initially present in both columns and therefore represent the first ion-exchange cycle which will be able to process the largest volume of salt solution. Each batch was run until the integral average cesium concentration in the effluent collected from the lag column reached the specified limit of $6.0 \mathrm{nCi} / \mathrm{g}$.

Table 9-3. Volume in thousands of gallons processed through SCIX ion-exchange columns during first cycle.

\begin{tabular}{|c|c|c|c|c|c|c|c|}
\hline & \multirow{3}{*}{$\begin{array}{l}\text { SCIX } \\
\text { Batch }\end{array}$} & \multirow{3}{*}{$\begin{array}{c}\text { Batch } \\
\text { Volume } \\
\text { (gal/1000) }\end{array}$} & \multicolumn{5}{|c|}{ Column Flow Rate and Operating Temperature } \\
\hline & & & $5 \mathrm{gpm}$ & 10 gpm & $20 \mathrm{gpm}$ & $10 \mathrm{gpm}$ & $10 \mathrm{gpm}$ \\
\hline & & & $35^{\circ} \mathrm{C}$ & $35^{\circ} \mathrm{C}$ & $35^{\circ} \mathrm{C}$ & $25^{\circ} \mathrm{C}$ & $45^{\circ} \mathrm{C}$ \\
\hline \multirow{4}{*}{$\begin{array}{c}\text { With } \\
\text { Caustic } \\
\text { Addition }\end{array}$} & 1 & 1,040 & 567 & 448 & 307 & 532 & 372 \\
\hline & 2 & 1,040 & 566 & 456 & 318 & 528 & 388 \\
\hline & 3 & 1,040 & 526 & 419 & 298 & 498 & 348 \\
\hline & 4 & 1,040 & 573 & 463 & 326 & 537 & 392 \\
\hline \multirow{2}{*}{$\begin{array}{l}\text { Without } \\
\text { Caustic } \\
\text { Addition }\end{array}$} & $\mathbf{1 x}$ & 1,005 & 570 & 457 & 318 & 545 & 378 \\
\hline & $2 x$ & 1,005 & 575 & 474 & 335 & 551 & 400 \\
\hline
\end{tabular}

Table 9-4 shows results from VERSE-LC modeling of three ion-exchange cycles for each SCIX batch under nominal operating conditions of $35^{\circ} \mathrm{C}$ and $10 \mathrm{gpm}$ flow rate. When each cycle is completed (i.e., when the bucket average effluent cesium concentration reaches 6.0 $\mathrm{nCi} / \mathrm{g}$ ) the lag column is placed in the lead position and a fresh lag column is added to the system. For all of the SCIX batches except Batch 3, three ion-exchange cycles are able to process the entire batch volume.

Table 9-4. Volume in thousands of gallons processed through SCIX ion-exchange columns during three cycles at nominal processing conditions.

\begin{tabular}{|c|c||c|c|c||c|}
\hline \multirow{2}{*}{} & \multicolumn{1}{|c||}{$\begin{array}{c}\text { SCIX } \\
\text { Batch }\end{array}$} & \multicolumn{4}{c|}{ Volume Processed (gal/1000) } \\
\cline { 2 - 6 } & Cycle 1 & Cycle 2 & Cycle 3 & Total \\
\hline \hline \multirow{3}{*}{$\begin{array}{c}\text { With } \\
\text { Caustic } \\
\text { Addition }\end{array}$} & $\mathbf{1}$ & 448 & 315 & 340 & 1,103 \\
\cline { 2 - 6 } & $\mathbf{2}$ & 456 & 314 & 334 & 1,104 \\
\cline { 2 - 6 } & $\mathbf{3}$ & 419 & 287 & 315 & 1,021 \\
\hline $\begin{array}{c}\text { Without } \\
\text { Caustic } \\
\text { Addition }\end{array}$ & $\mathbf{1 x}$ & 463 & 316 & 339 & 1,118 \\
\cline { 2 - 6 } & $\mathbf{2 x}$ & 474 & 316 & 338 & 1,111 \\
\hline
\end{tabular}


Bucket average breakthrough curves for each of the six feed batches during the first ionexchange cycle for the nominal case of operation at $35^{\circ} \mathrm{C}$ and $10 \mathrm{gpm}$ are plotted in Figure 9-3. The breakthrough curves are all relatively sharp. For all six feed compositions, the width of the breakthrough front from $2.0 \mathrm{nCi} / \mathrm{g}$ to $6.0 \mathrm{nCi} / \mathrm{g}$ under nominal operating conditions is approximately 24,000 gallons. At a flow rate of $10 \mathrm{gpm}$, the corresponding breakthrough time between bucket average cesium concentrations of 2.0 and $6.0 \mathrm{nCi} / \mathrm{g}$ is about 40 hours. For all of the feed compositions, the difference in the volume of solution that can be processed between reaching an effluent cesium concentration of $6.0 \mathrm{nCi} / \mathrm{g}$ and reaching a bucket average concentration of $6.0 \mathrm{nCi} / \mathrm{g}$ under nominal operating conditions is 41,000 gallons $\pm 1,000$ gallons.

Column profiles showing the concentration of cesium in the liquid phase down the lead and lag columns at the end of an ion-exchange cycle for the six batch compositions tested are shown in Figures 9-4 through 9-15. The figures are presented in pairs for each batch where the first figure shows the profile as a function of flow rate at a constant temperature of $35^{\circ} \mathrm{C}$ and the second figure shows the profile as a function of operating temperature at a constant flow rate of $10 \mathrm{gpm}$. Column breakthrough is clearly more sensitive to flow rate than temperature. In all cases, at the nominal flow rate of $10 \mathrm{gpm}$, the lead column is very close to being fully loaded at the end of the cycle. Therefore, the assumption of a fully loaded column can be used to estimate maximum cesium loadings and is slightly conservative. Using the $50 \%$ breakthrough point to estimate lag column loading, at the nominal flow rate of $10 \mathrm{gpm}$, the lag columns are between $20 \%$ and $40 \%$ loaded at the end of a cycle.

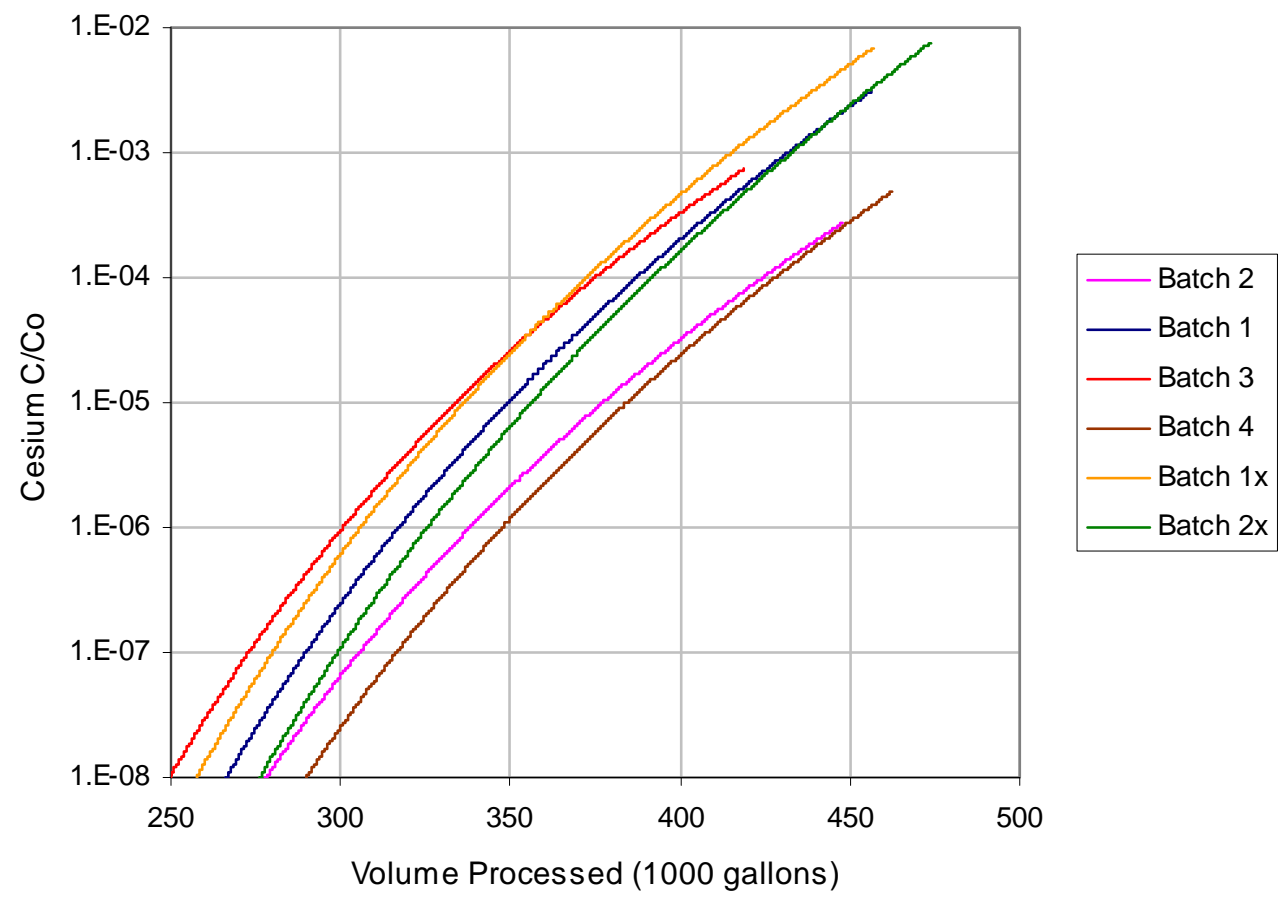

Figure 9-3. Lag column breakthrough curves for SCIX Batches 1-4 at nominal operating conditions of $35^{\circ} \mathrm{C}$ and $10 \mathrm{gpm}$ flow rate. 


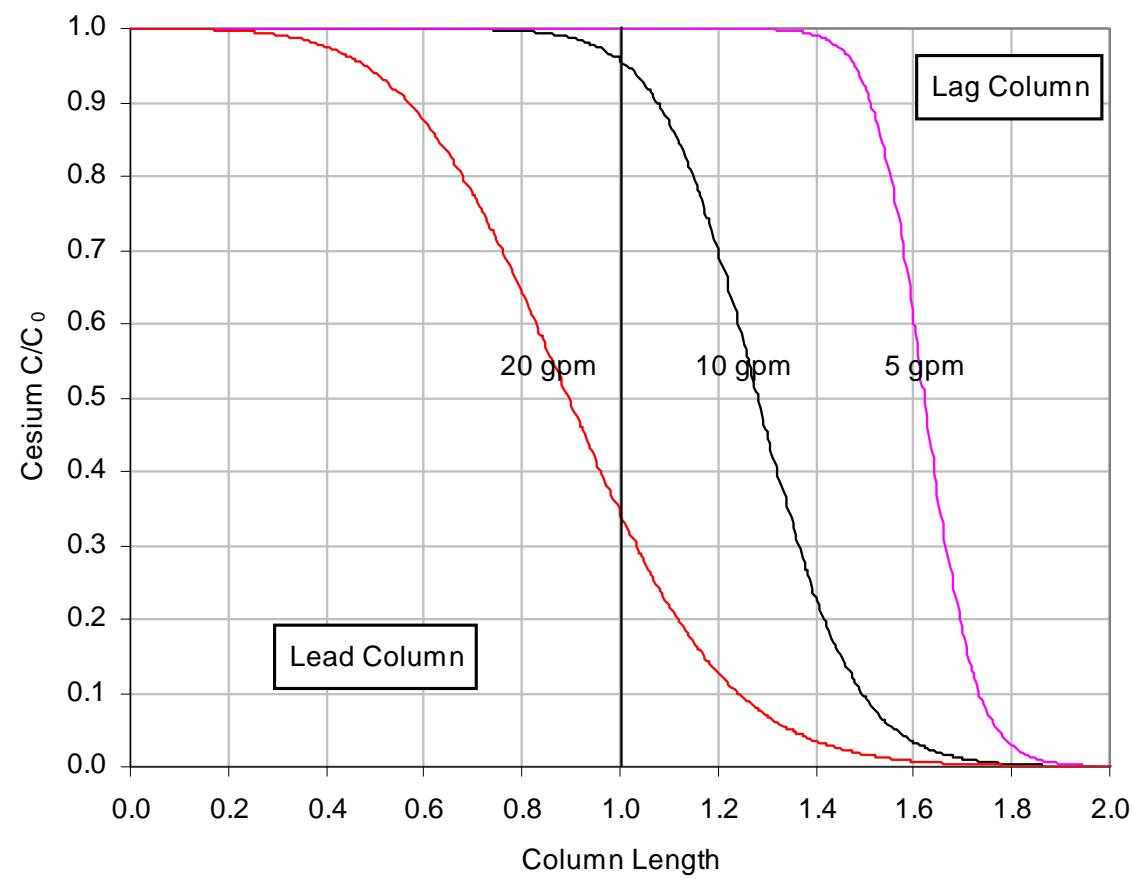

Figure 9-4. Cesium profile in columns at end of cycle for Batch 1 SCIX feed as a function of flow rate at $35^{\circ} \mathrm{C}$.

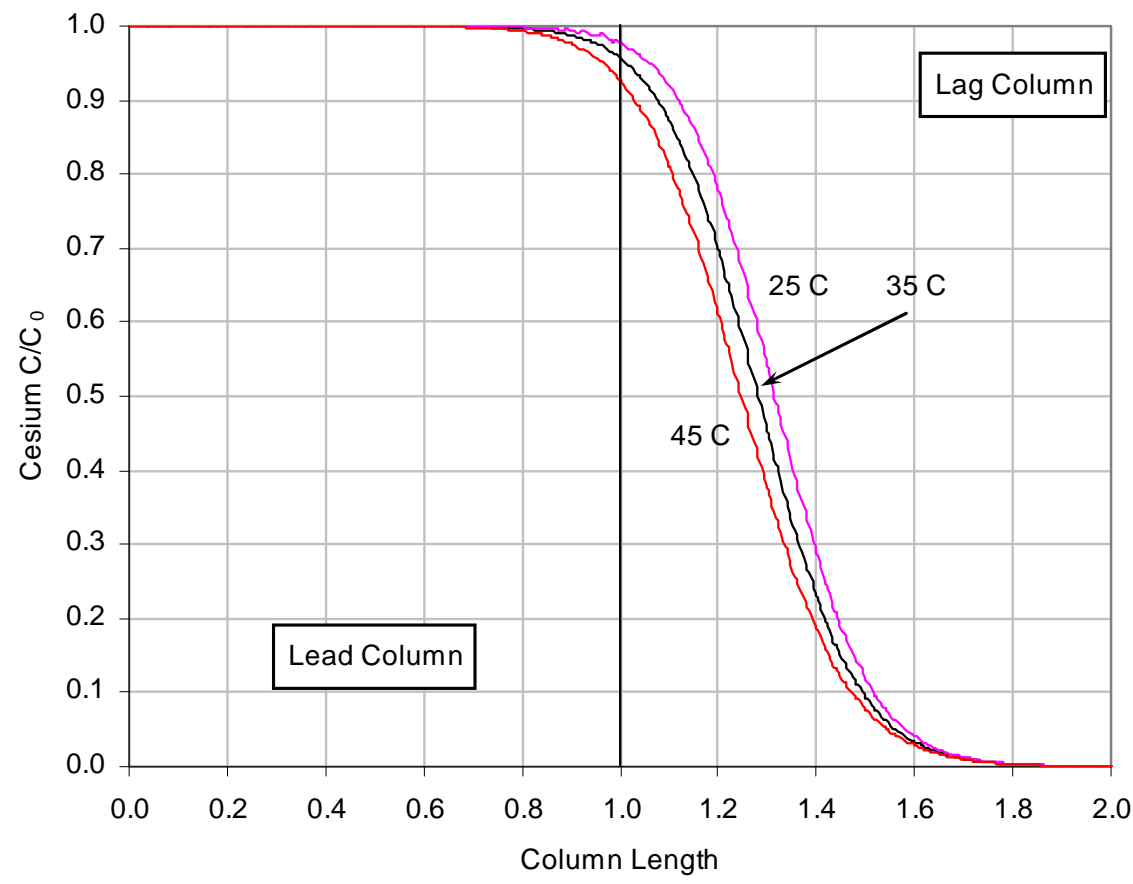

Figure 9-5. Cesium profile in columns at end of cycle for Batch 1 SCIX feed as a function of temperature at $10 \mathrm{gpm}$ flow. 


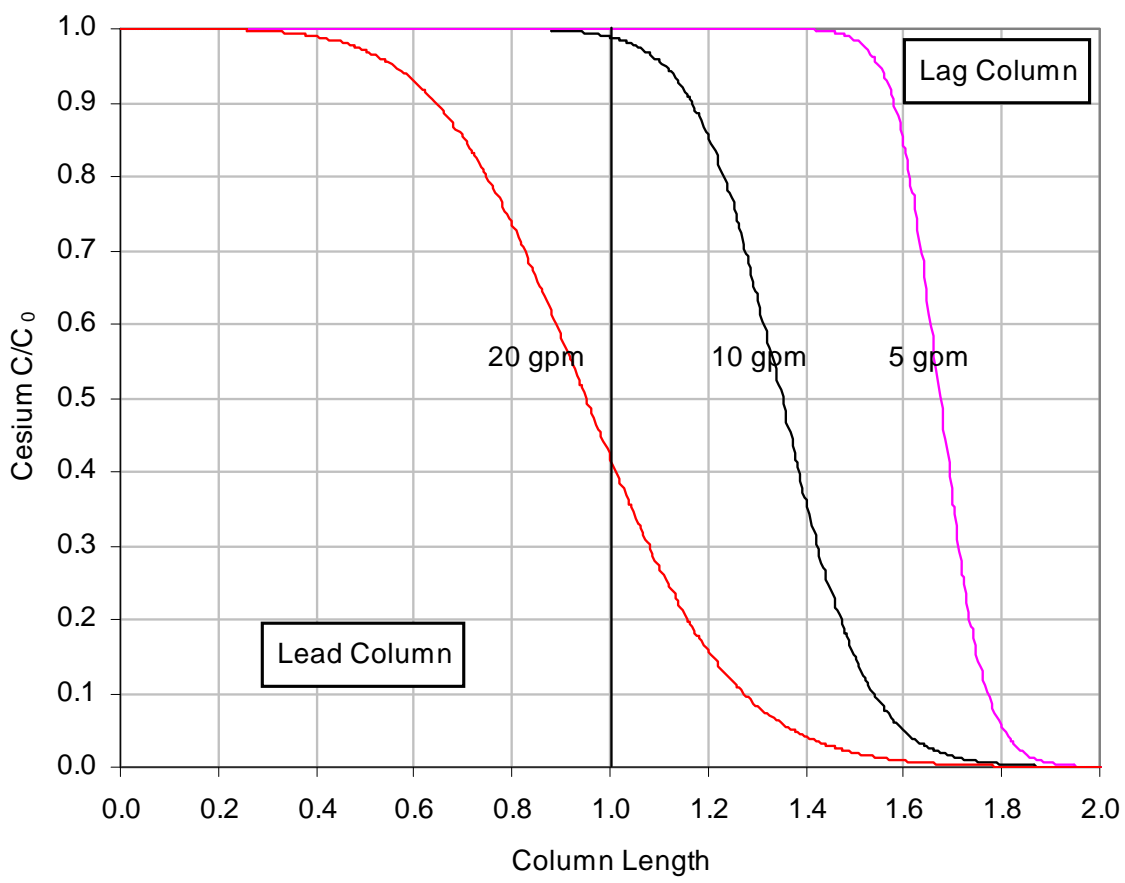

Figure 9-6. Cesium profile in columns at end of cycle for Batch 2 SCIX feed as a function of flow rate at $35^{\circ} \mathrm{C}$.

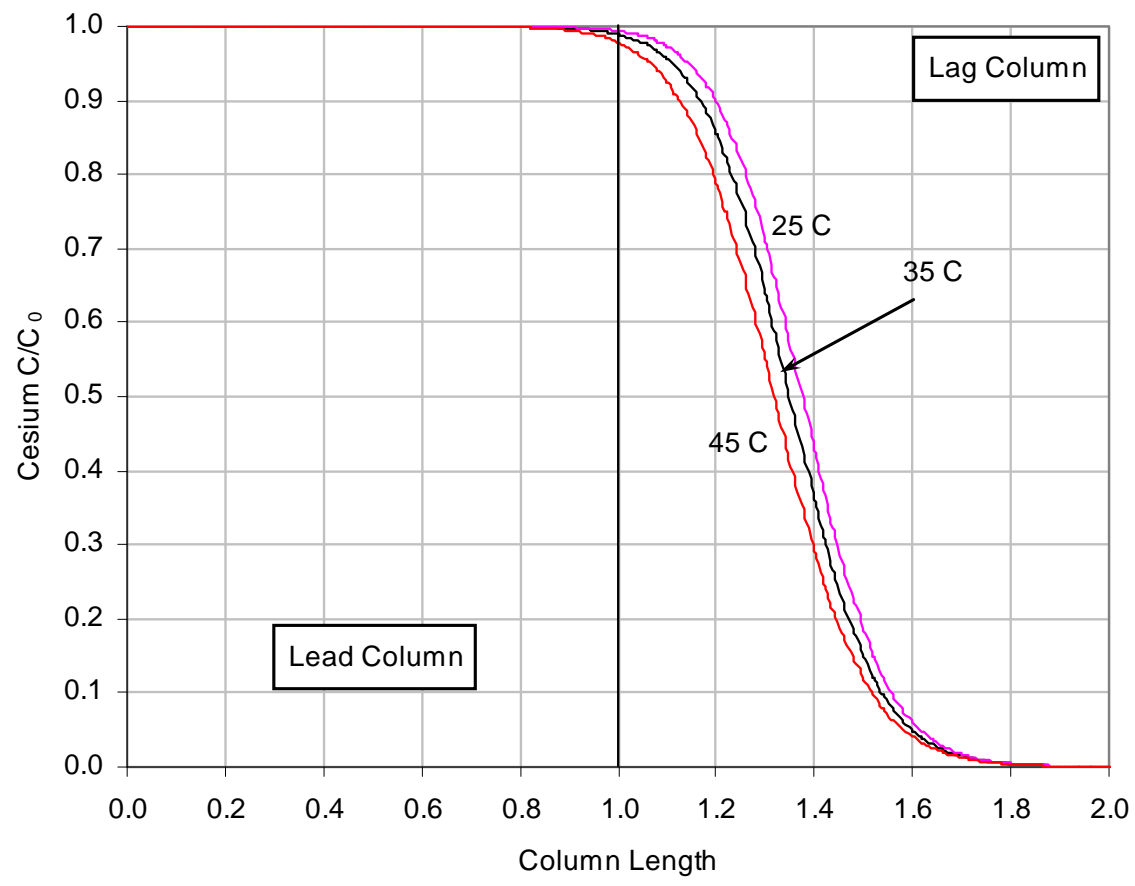

Figure 9-7. Cesium profile in columns at end of cycle for Batch 2 SCIX feed as a function of temperature at $10 \mathrm{gpm}$ flow. 


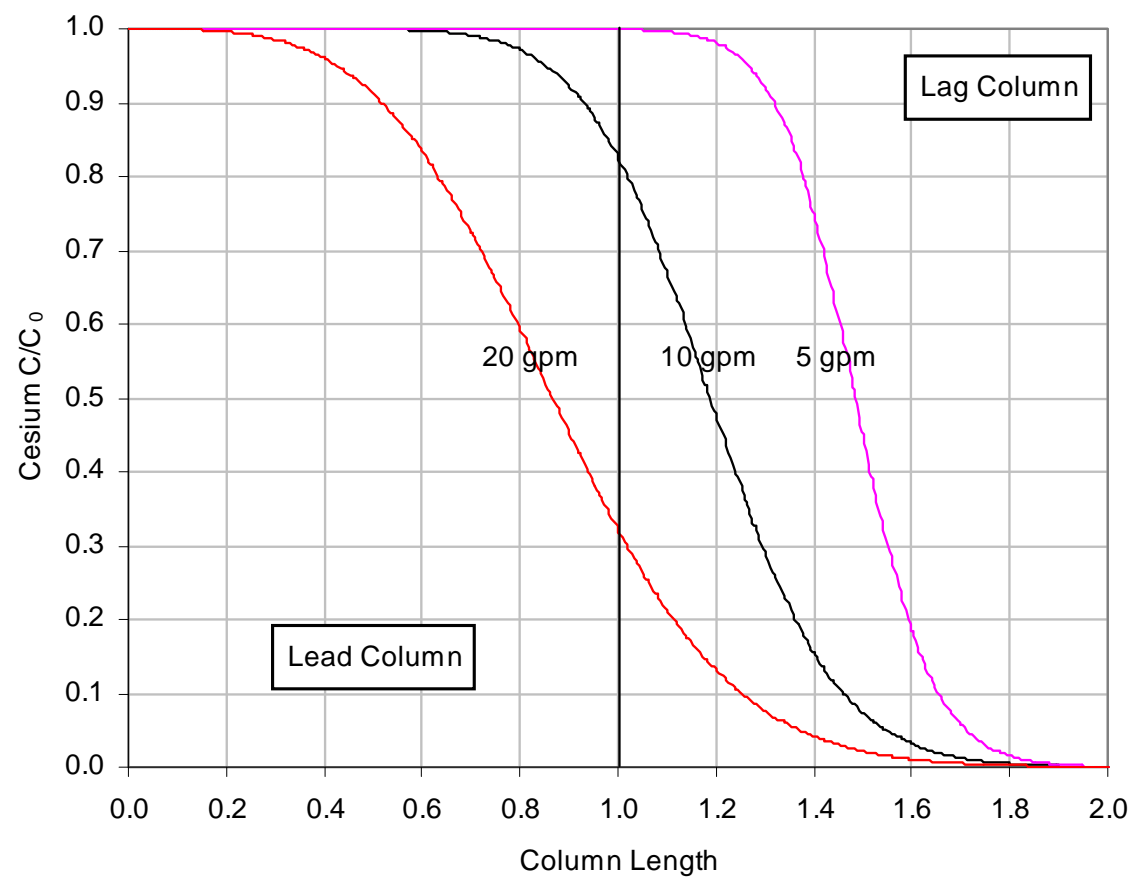

Figure 9-8. Cesium profile in columns at end of cycle for Batch 3 SCIX feed as a function of flow rate at $35^{\circ} \mathrm{C}$.

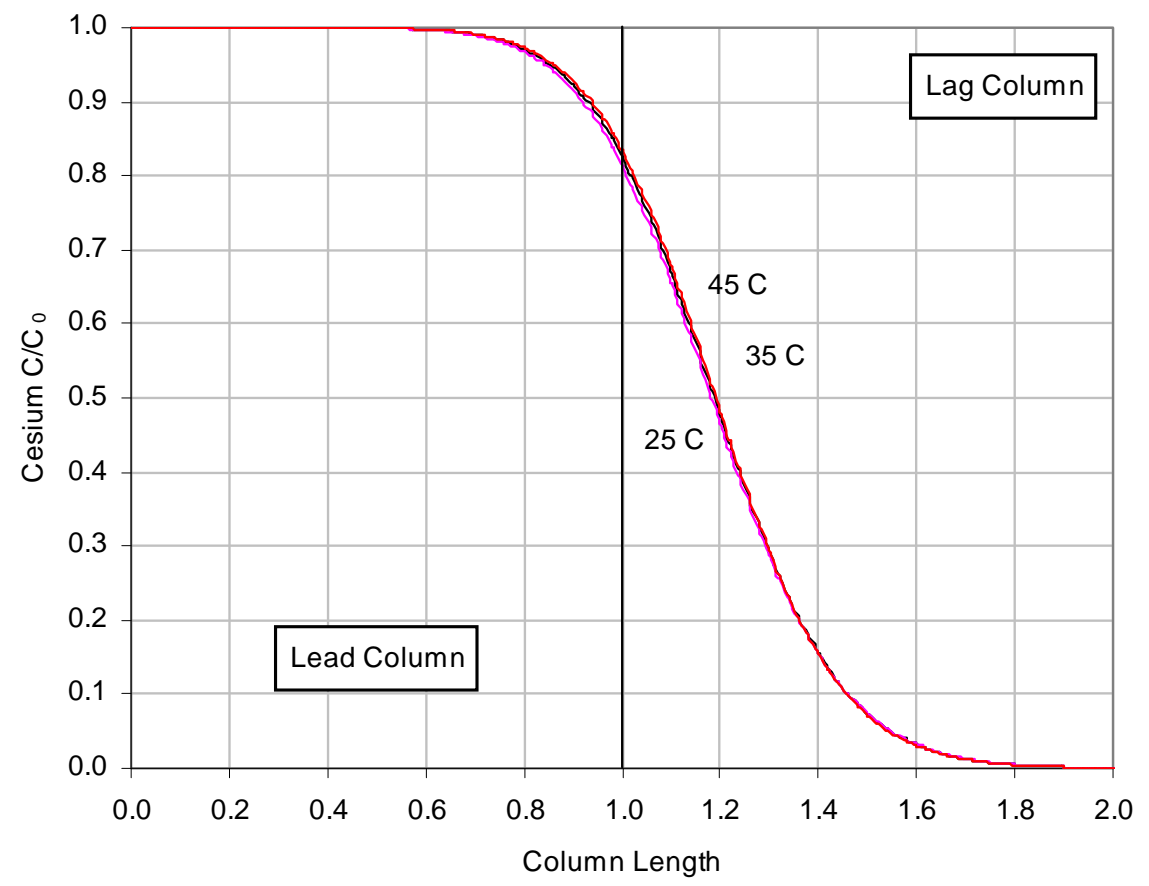

Figure 9-9. Cesium profile in columns at end of cycle for Batch 3 SCIX feed as a function of temperature at $10 \mathrm{gpm}$ flow. 


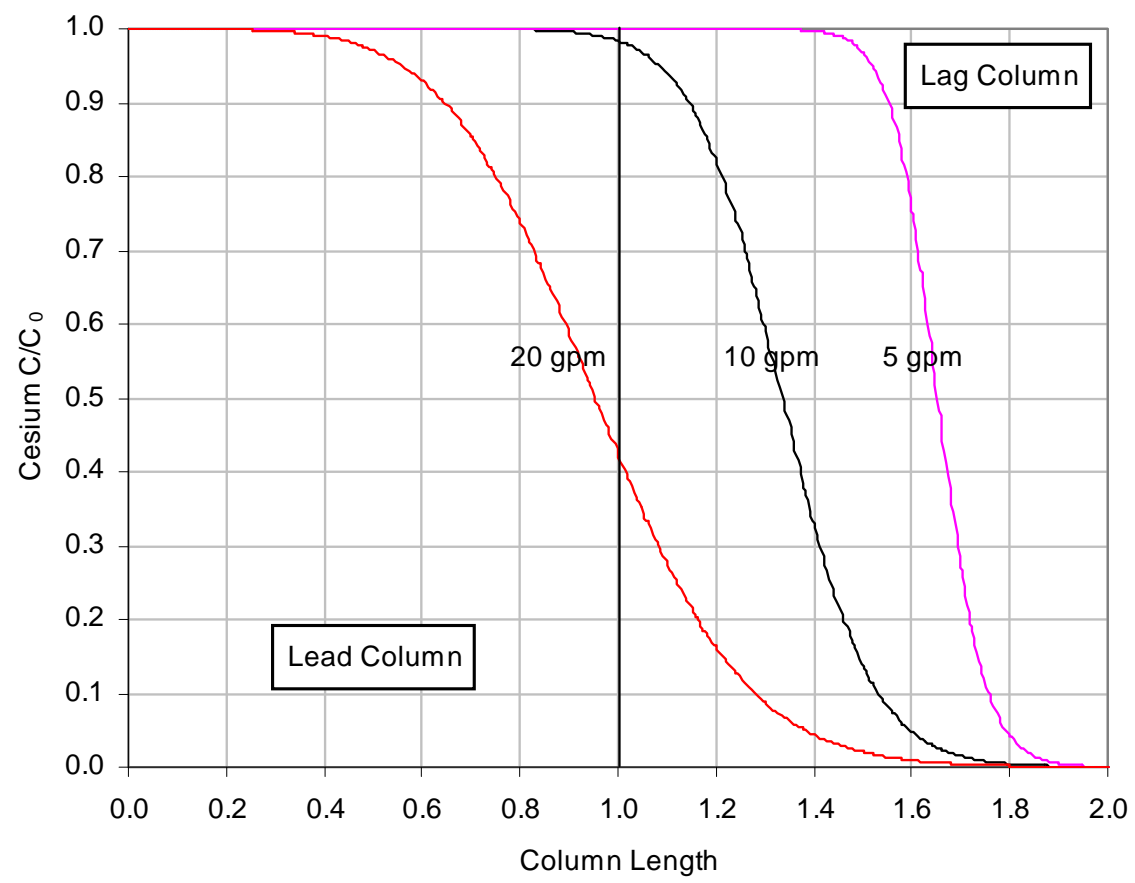

Figure 9-10. Cesium profile in columns at end of cycle for Batch 4 SCIX feed as a function of flow rate at $35^{\circ} \mathrm{C}$.

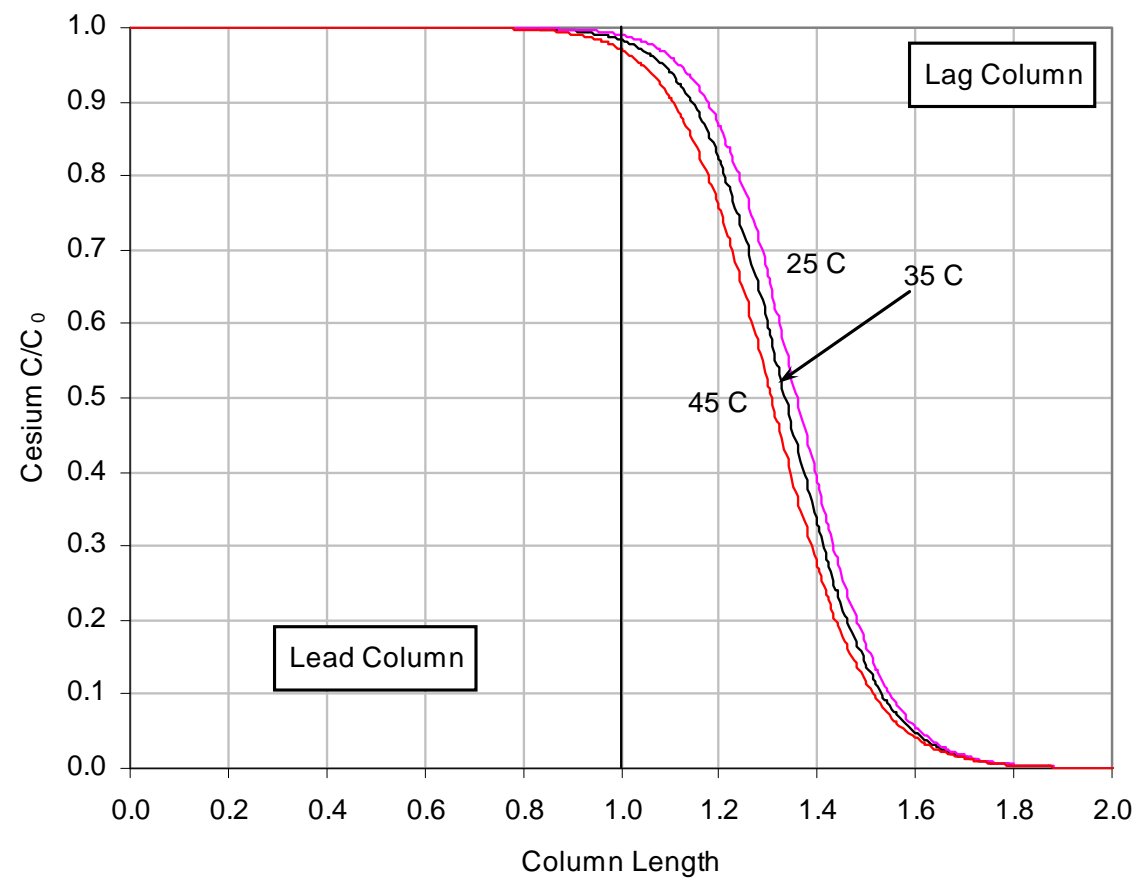

Figure 9-11. Cesium profile in columns at end of cycle for Batch 4 SCIX feed as a function of temperature at $10 \mathrm{gpm}$ flow. 


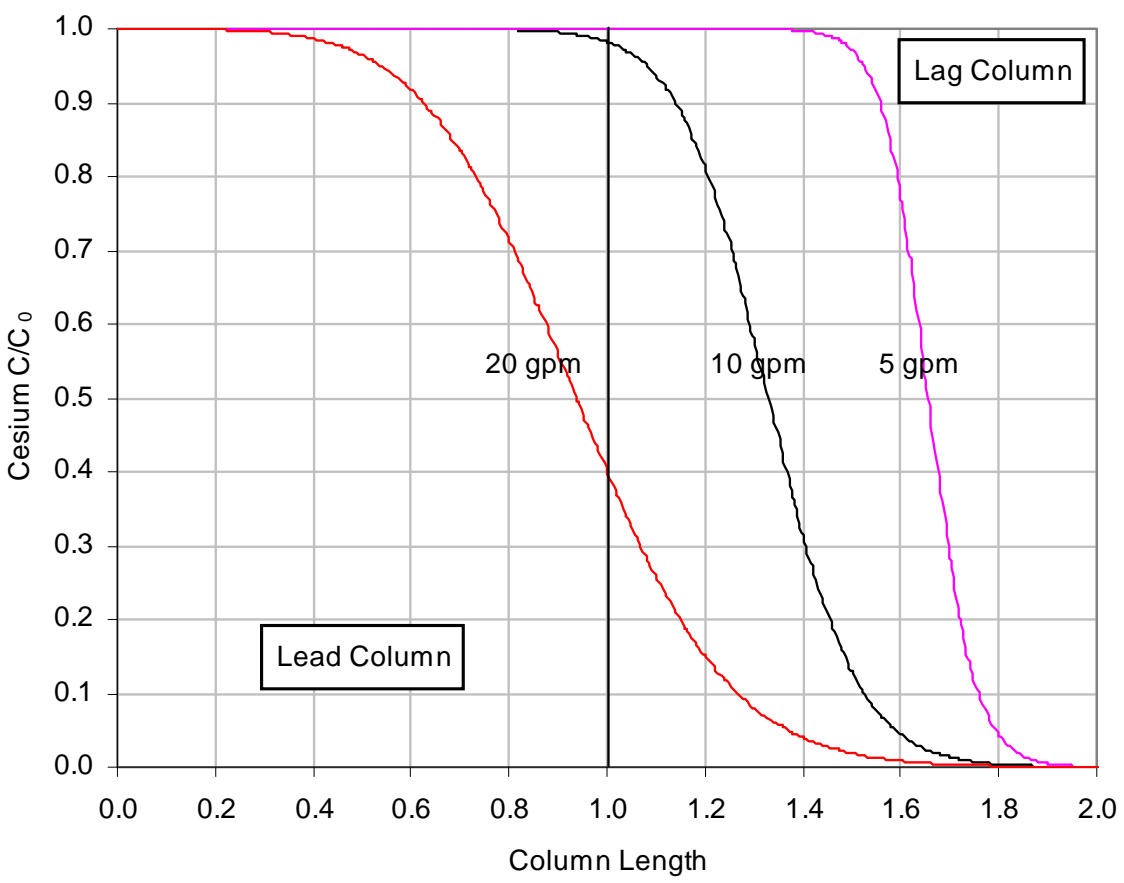

Figure 9-12. Cesium profile in columns at end of cycle for Batch 1 SCIX feed without caustic addition as a function of flow rate at $35^{\circ} \mathrm{C}$.

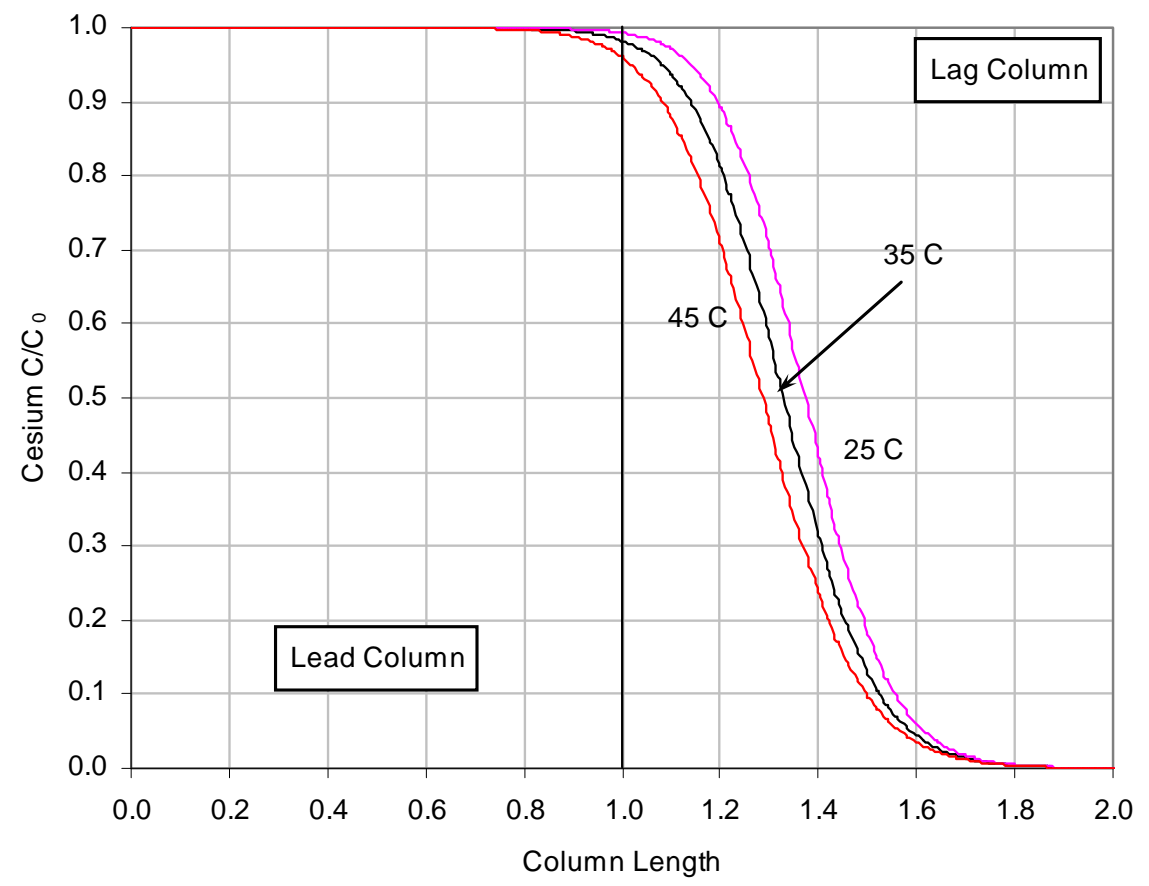

Figure 9-13. Cesium profile in columns at end of cycle for Batch 1 SCIX feed without caustic addition as a function of temperature at $10 \mathrm{gpm}$ flow. 


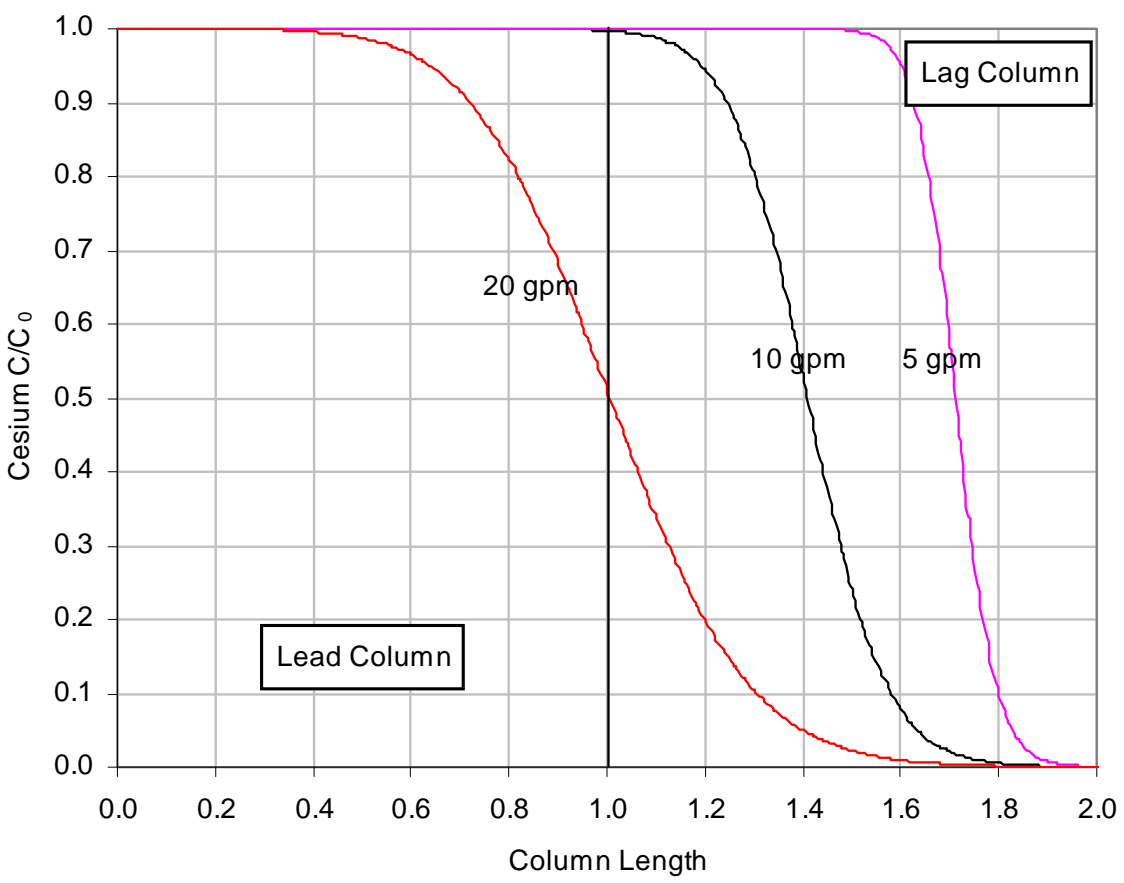

Figure 9-14. Cesium profile in columns at end of cycle for Batch 2 SCIX feed without caustic addition as a function of flow rate at $35^{\circ} \mathrm{C}$.

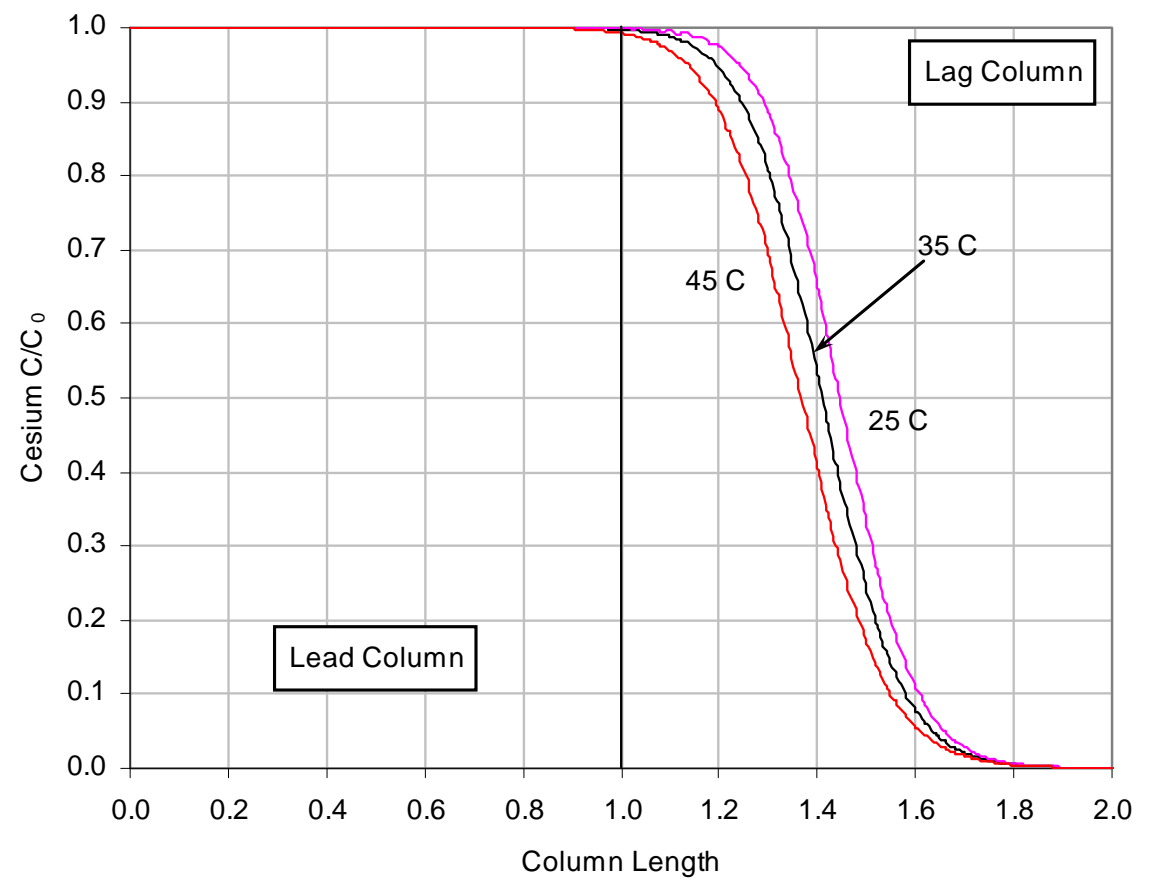

Figure 9-15. Cesium profile in columns at end of cycle for Batch 2 SCIX feed without caustic addition as a function of temperature at $10 \mathrm{gpm}$ flow. 


\subsection{Conclusions}

For all of the SCIX feed compositions, modeling showed that CST was able to process a significant volume of caustic salt solution during each ion-exchange cycle. The volume of solution that can be processed during the first ion-exchange cycle, when both columns initially contain fresh CST, for each SCIX batch is shown in Table 9-3 for all operating conditions tested. The volume of solution that can be processed during the first three ionexchange cycles under nominal operating conditions of $35^{\circ} \mathrm{C}$ and $10 \mathrm{gpm}$ flow rate is shown in Table 9-4 for each SCIX batch. Cesium loading on the CST was much greater than found during the 2007 SCIX study primarily because of the increased hydroxide concentration in the feed. General results from the ZAM/VERSE model predictions are:

- Lower flow sharpens the breakthrough front and allows more volume to be processed in each ion-exchange cycle. On average, decreasing the flow rate from 10 gpm to $5 \mathrm{gpm}$ increased the volume of solution processed by $26 \%$ while doubling the time required to run the material through the column.

- Higher flow spreads out the breakthrough front and decreases the amount of solution that can be processed in each ion-exchange cycle. This results in greater CST usage to process a given feed volume. On average, doubling the flow from $10 \mathrm{gpm}$ to 20 gpm decreased the volume of solution processed by $30 \%$, while also decreasing the time required to run the material through the column by a factor of two.

- Operating the column at elevated temperature decreases the adsorption capacity of the resin and decreases the amount of solution that can be treated in each cycle. On average, operating at $45^{\circ} \mathrm{C}$ instead of $35^{\circ} \mathrm{C}$ decreased the CST capacity by $16 \%$.

- Operating the column at lower temperature increases the adsorption capacity of the resin and increases the amount of solution that can be treated in each cycle. On average, operating at $25{ }^{\circ} \mathrm{C}$ instead of $35{ }^{\circ} \mathrm{C}$ increased the CST capacity by $18 \%$.

- At the nominal operating conditions of $10 \mathrm{gpm}$ and $35^{\circ} \mathrm{C}$, starting with two fresh columns at the start of processing, it will take between two and three ion-exchange cycles per batch to process SCIX Batches $1-4$. The model predicts that SCIX Batch 3 would require slightly more than three ion-exchange cycles under nominal operating conditions.

- At the end of each cycle, under nominal operating conditions, the lead column will be loaded to greater than $98 \%$ of full capacity while the lag column will be from $20 \%$ to $40 \%$ loaded.

- For the SCIX feed compositions given in Table 2-1, strontium does not load onto CST to any significant extent. On average, increasing the rubidium concentration in the feed by a factor of 10 decreased cesium loading by $3 \%$. 


\subsection{References}

Aleman, S. E., 2003. "Small Column Ion Exchange Analysis for Removal of Cesium from SRS Low Curie Salt Solutions Using Crystalline Silicotitanate (CST) Resin," WSRCTR-2003-00430, Rev. 1, January 2004.

Anderko, A. and M. M. Lencka, 1977. "Computation of Electrical Conductivity of Multicomponent Aqueous Systems in Wide Concentration and Temperature Ranges," Ind. Eng. Chem. Res., 1997, 36, pp. 1932-1943.

Behrouzi, A. M., 2011. "Technical task Request: SCIX Feed Modeling," HLE-TTR-2011003, January 25, 2011.

Berninger, J., R. D. Whitley, X. Zhang and N.-H.L. Wang, 1991. "A Versatile Model for Simulation of Reaction and Nonequilibrium Dynamics in Multicomponent Fixed-Bed Adsorption Processes," Comput. Chem. Eng., 1991, 15 (11), pp. 749-768.

Bird, R. B., W. E. Stewart and E. N. Lightfoot, 1960. Transport Phenomena, John Wiley and Sons, Inc., New York.

Brooks, K. P., 1994. "Cesium Ion Exchange using Actual Waste: Column Size Considerations,” TWRSPP-94-091, Battelle PNL, September 1994.

Chung, S. F. and C. Y. Wen, 1968. "Longitudinal Dispersion of Liquid Flowing Through Fixed and Fluidized Beds," AIChE J., 14 (6), pp. 857-866.

Foo, S. C. and R. G. Rice, 1975. "On the Predication of Ultimate Separation in Parametric Pumps," AIChE J., 21 (6), pp. 1149-1158.

Glasstone, S. and D. Lewis, 1960. Elements of Physical Chemistry, D. Van Nostrand Company, Inc., Princeton, N.J.

Hamm, L. L., F. G. Smith and M. A. Shadday, 2000. "QA Verification Package for VERSELC Version 7.80,” WSRC-TR-99-00238, Rev. 0, February 2000.

Hamm, L. L., T. Hang, D. J. McCabe and W. D. King, 2002. "Preliminary Ion Exchange Modeling for Removal of Cesium from Hanford Waste Using Hydrous Crystalline Silicotitanate Material,” WSRC-TR-2001-00400 (SRT-RPP-2001-00134), Rev. 0, July 2002.

Perry, R. H., C. H. Chilton and S. D. Kirkpatrick, (eds.) 1973. Chemical Engineer's Handbook, $5^{\text {th }}$ ed., McGraw-Hill, New York.

Reid, R. C., J. M. Prausnitz and T. K. Sherwood, 1977. The Properties of Gases and Liquids, $3^{\text {rd }}$ ed., McGraw-Hill Chemical Engineering Series, McGraw-Hill Book Company, Inc., New York. pp. 590-592.

Smith, F. G., 2007. "Modeling of Ion-Exchange for Cesium Removal from Dissolved Saltcake in SRS Tanks 1-3, 37 and 41", WSRC-STI-2007-00315, Rev. 0, August, 2007.

Walker, D. D., D. J. Adamson, T. D. Allen, R. W. Blessing, W. T. Boyce, B. H. Croy, R. A. Newberry, D. P. Diprete, S. D. Fink, T. Hang, J. C. Hart, M. C. Lee, J. J. Olson and M. J. Whitaker, 1999. "Cesium Removal from Savannah River Site Radioactive Waste using Crystalline Silicotitanate (IONSIV ${ }^{\circledR}$ IE-911)," WSRC-TR-99-00308, Revision 0, September 1999.

Whitley, R. D. and N.-H. Wang, 1998. "User's Manual VERSE (VErsatile Reaction Seperation) Simulation for Liquid Phase Adsorption and Chromatography Processes," School of Chemical Engineering, Purdue University, July 1998. 
Wilson, E. J. and C. J. Geankoplis, 1966. "Liquid Mass Transfer at Very Low Reynolds Numbers in Packed Beds," Ind. Eng. Chem. Fund., 1966, 5 (1), pp. 9-14.

Zheng, Z., R. G. Anthony and J. E. Miller, 1997. "Modeling Multicomponent Ion Exchange Equilibrium Utilizing Hydrous Crystalline Silicotitanates by a Multiple Interactive Ion Exchange Site Model," Ind. Eng. Chem. Res., 1997, 36, pp. 2427-2434. 